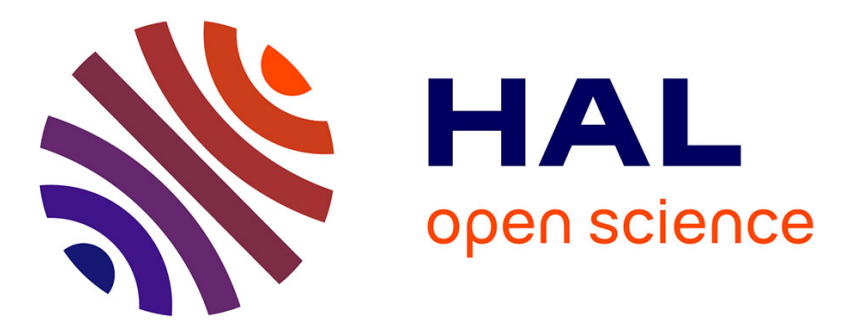

\title{
Investigation of the polyamine biosynthetic and transport capability of Streptococcus agalactiae: the non-essential PotABCD transporter
}

Sarah Khazaal, Rim Al Safadi, Dani Osman, Aurélia Hiron, Philippe Gilot

\section{To cite this version:}

Sarah Khazaal, Rim Al Safadi, Dani Osman, Aurélia Hiron, Philippe Gilot. Investigation of the polyamine biosynthetic and transport capability of Streptococcus agalactiae: the non-essential PotABCD transporter. Microbiology, 2021, 167 (12), 15 p. 10.1099/mic.0.001124 . hal-03529469

\author{
HAL Id: hal-03529469 \\ https://hal.inrae.fr/hal-03529469
}

Submitted on 17 Jan 2022

HAL is a multi-disciplinary open access archive for the deposit and dissemination of scientific research documents, whether they are published or not. The documents may come from teaching and research institutions in France or abroad, or from public or private research centers.
L'archive ouverte pluridisciplinaire HAL, est destinée au dépôt et à la diffusion de documents scientifiques de niveau recherche, publiés ou non, émanant des établissements d'enseignement et de recherche français ou étrangers, des laboratoires publics ou privés.

\section{(c)(1)}

Distributed under a Creative Commons Attribution| 4.0 International License 


\title{
Investigation of the polyamine biosynthetic and transport capability of Streptococcus agalactiae: the non-essential PotABCD transporter
}

\author{
Sarah Khazaal ${ }^{1,2}$, Rim Al Safadi², Dani Osman², Aurélia Hiron ${ }^{1}$ and Philippe Gilot ${ }^{1, *}$
}

\begin{abstract}
Polyamines constitute a group of organic polycations positively charged at physiological pH. They are involved in a large variety of biological processes, including the protection against physiological stress. In this study, we show that the genome of Streptococcus agalactiae, a commensal bacterium of the intestine and the vagina and one of the most common agents responsible of neonate infections, does not encode proteins homologous to the specific enzymes involved in the known polyamine synthetic pathways. This lack of biosynthetic capability was verified experimentally by TLC analysis of the intracellular content of $S$. agalactiae grown in the absence of polyamines. However, similar analyses showed that the polyamines spermidine, spermine and putrescine can be imported from the growth media into the bacteria. We found that all strains of S. agalactiae possess the genes encoding the polyamine ABC transporter PotABCD. We demonstrated that these genes form an operon with folK, a gene involved in folate biosynthesis, murB, a gene involved in peptidoglycan biosynthesis, and with clc, a gene encoding a $\mathrm{Cl}^{-} / \mathrm{H}^{+}$antiporter involved in resistance to acid stress in Escherichia coli. Transcription of the potABCD operon is induced by peroxide-induced oxidative stress but not by acidic stress. Spermidine and spermine were found to be inducers of potABCD transcription at pH 7.4 whereas putrescine induces this expression only during peroxide-induced oxidative stress. Using a deletion mutant of pot $A B C D$, we were nevertheless unable to associate phenotypic traits to the PotABCD transporter, probably due to the existence of one or more as yet identified transporters with a redundant action.
\end{abstract}

\section{INTRODUCTION}

Polyamines, small aliphatic hydrocarbon molecules with a quaternary nitrogen chemical group, have a net positive charge at physiological $\mathrm{pH}$. They are associated with a large range of biological functions such as efficient DNA replication, transcription, translation, stress resistance, cell proliferation and differentiation $[1,2]$. Together with $\mathrm{Mg}^{2+}$ and $\mathrm{Ca}^{2+}$, polyamines constitute the major polycations in cells. They are able to bind to intracellular polyanions such as nucleic acids and ATP to modulate their functions. Putrescine (1,4-diaminobutane), spermidine [ $N$-(3-aminopropyl)butane-1,4-diamine], spermine [N,N'-bis (3-aminopropyl)butane-1,4-diamine] and cadaverine (1,5-diaminopentane) are the most widely distributed cellular polyamines and are essential for normal multiplication and cellular growth of most prokaryotic and eukaryotic cells [2]. Polyamines appear to play a crucial role in the pathogenesis and virulence of important human bacterial pathogens. Several studies, in species such as Escherichia coli and Streptococcus pneumoniae, involved polyamines in the protection of bacterial cells from the toxic effects of reactive oxygen, by their function of radical scavengers [3, 4]. In addition, polyamines are key mediators in the resistance to acidic stress in several bacterial species. For example, in E. coli and Salmonella enterica, they induce the expression of amino acid decarboxylases, which are directly involved in the response of these bacteria to acidic stress, and thus facilitate their survival in vivo $[5,6]$. The pleiotropic effects of polyamines on nucleic acid stability, transcription and translation also play an important role in the physiological adaptation of $S$. pneumoniae during temperature stress [4]. The physiological functions of polyamines cannot take place without a highly regulated level of intracellular polyamines, which is based on

Received 13 October 2021; Accepted 11 November 2021; Published 15 December 2021

Author affiliations: 'ISP, Bactéries et Risque Materno-Foetal, Université de Tours, INRAE, 37032 Tours, France; ${ }^{2}$ Azm Center for Research in Biotechnology and its Applications, LBA3B, EDST, Lebanese University, Tripoli, 1300, Lebanon.

*Correspondence: Philippe Gilot, philippe.gilot@inrae.fr

Keywords: $A B C$ transporter; oxidative stress; polyamines

Abbreviations: ABC, ATP-binding cassette; IS, insertion sequence; TLC, thin-layer chromatography.

Six supplementary figures are available with the online version of this article.

001124 (c) 2021 The Authors 


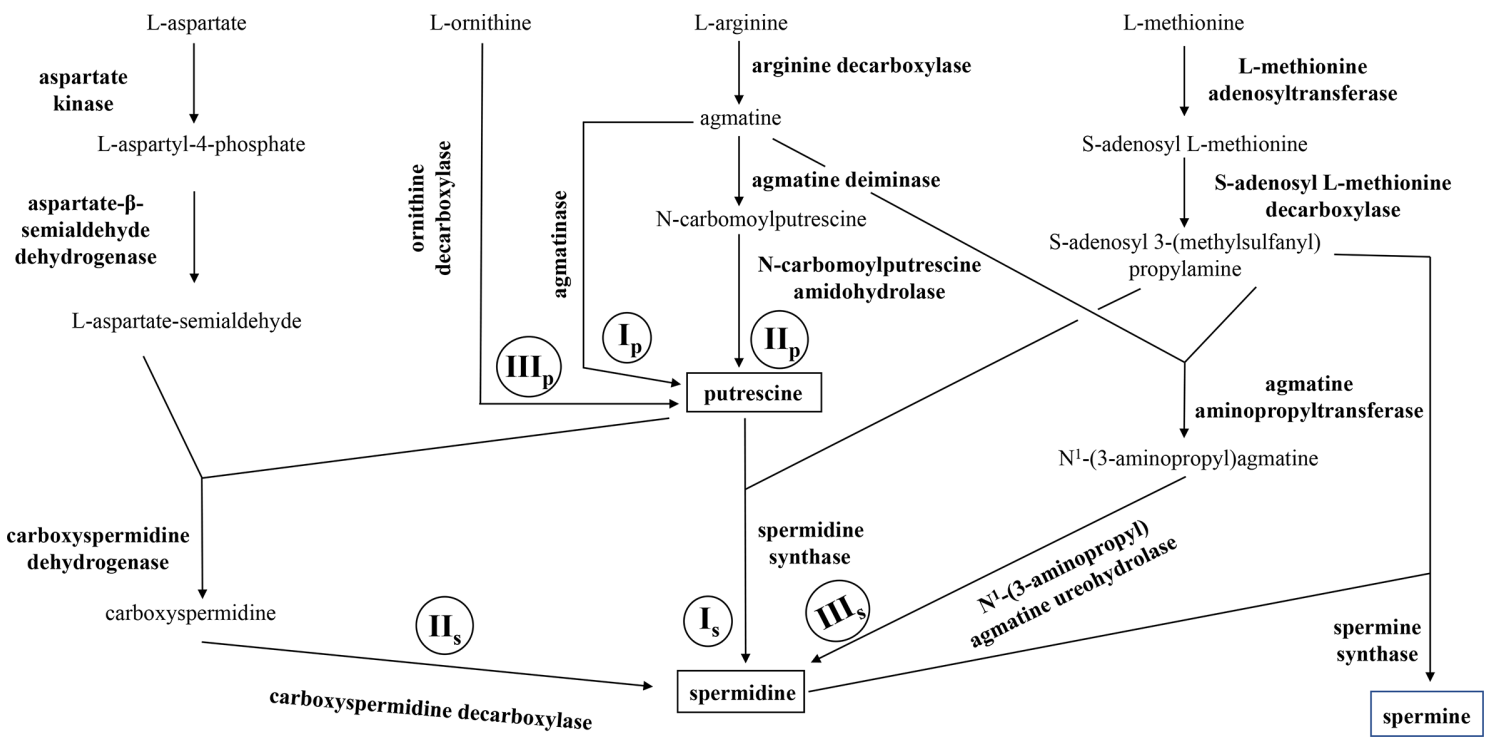

Fig. 1. Known de novo polyamine biosynthetic pathways in microorganisms. Three pathways for the biosynthesis of putrescine (Ip, Ilp, IIIp), two for the biosynthesis of spermidine (Is, IIs) and one for the biosynthesis of spermine are described in microorganisms.

the coordination of the processes of the polyamine uptake, synthesis and degradation [2]. Most prokaryotes have de novo biosynthesis pathways in which polyamines are generated via enzymatic modification of amino acid precursors [7]. In addition, almost all bacteria possess polyamine transport systems to satisfy their requirements from the environment [8].

Three pathways of putrescine biosynthesis (Ip, IIp and IIIp; Fig. 1) and three pathways of spermidine biosynthesis (Is, IIs and IIIs; Fig. 1) have been described in bacteria [9-16]. In Saccharomyces cerevisiae, spermine can be synthesized by the addition of a propylamine group to spermidine, a reaction catalysed by spermine synthase (Fig. 1) [17]. However, although the presence of spermine is attested to in several bacterial species, no specific bacterial spermine synthase has yet been discovered [18]. Polyamines are not biosynthesized by all bacterial species. For example, in the genus Streptococcus, while polyamine biosynthesis pathways (IIp, Is and IIs) are present in all strains of $S$. pneumoniae, they are lacking in the majority of the strains of Streptococus suis and Streptococcus mitis, which must acquire polyamines from the environment [19].

Almost all bacteria can also import extracellular polyamines by a polyamine ATP-binding cassette $(\mathrm{ABC})$ transporter, encoded by an operon of four genes $[4,20,21]$. Some bacteria, such as E. coli, possess two polyamine ABC transporters, PotABCD and PotFGHI, having a higher affinity for either spermidine or putrescine, respectively [22, 23]. Only a single pot $A B C D$ operon is detected in many other bacteria, such as Staphylococcus aureus, S. pneumoniae, S. suis or Streptococcus agalactiae [19, 24-27]. PotA and PotG are membrane-associated cytosolic ATPases. PotB with PotC or PotH with PotI constitute transmembrane channels for polyamine transport. Located in the periplasm or anchored to the cytoplasmic membrane, PotD and PotF are substrate-binding proteins that trap extracellular polyamines $[22,23]$. The binding of polyamine to the substratebinding proteins results in a conformational change of the membrane spanning proteins of the transporter, which leads to ATP hydrolysis and polyamine uptake. The presence of excess polyamines in the environment can function as a feedback regulator on polyamine transport. It was shown in E. coli that a high concentration of spermidine can inhibit the polyamine transport system, by the inhibition of ATPase activity, through the interaction of spermidine with a domain of PotA [28]. In addition, PotD is also able to inhibit the transcription of the pot $A B C D$ operon of E. coli [8].

S. agalactiae, also called Group B Streptococcus, was first distinguished from other streptococci by Rebecca Lancefield in 1930, after it was isolated from milk, and was detected as a primordial cause of mastitis in cows [29]. It is a Gram-positive, $\beta$-haemolytic bacterium, which frequently and asymptomatically colonizes the gastrointestinal and/ or urogenital tract of humans [30]. S. agalactiae maternal carriage was identified as a high risk factor for the development of neonatal disease and preterm birth [31]. In neonates, S. agalactiae is one of the leading causes of invasive infections, such as pneumonia, septicaemia and meningitis [32]. It has also emerged as an increasingly common cause of invasive diseases in immunocompromised and elderly adults [33]. In addition to its ability to colonize the gastrointestinal and uro-genital tracts, S. agalactiae also colonizes the throat or the oral and nasopharyngeal mucosa. Furthermore, it is able to infect the amniotic and cerebrospinal fluids, the blood and the mammary gland [34-37]. Moreover, S. agalactiae can contaminate foodstuffs, and it has been isolated from 
Table 1. Bacterial strains and plasmids used in this study

\begin{tabular}{|c|c|c|}
\hline Strain or plasmid & Genotype or description & $\begin{array}{l}\text { Source or } \\
\text { reference }\end{array}$ \\
\hline \multicolumn{3}{|l|}{ E. coli strain } \\
\hline XL1-blue & $\begin{array}{l}\text { endA1 gyrA96 }\left(\mathrm{Nal}^{\mathrm{R}}\right) \text { thi-1 recA1 } \\
\text { relA1 lac glnV44 hsdR17( } \mathrm{r}_{\mathrm{K}-} \mathrm{m}_{\mathrm{K}+)} \\
\mathrm{F}^{\prime}\left[:: \mathrm{Tn} 10\left(\mathrm{Tet}^{\mathrm{R}}\right) \text { proAB } \text { lacl }^{\mathrm{K}}\right. \\
Z \Delta M 15]\end{array}$ & Stratagene \\
\hline \multicolumn{3}{|l|}{ S. agalactiae strains } \\
\hline A909 & $\begin{array}{l}\text { Isolated from a septic human } \\
\text { neonate in } 1934 \text { (ST 7, CC 7) }\end{array}$ & {$[40]$} \\
\hline A909 $\triangle$ pot $A B C D$ & $\begin{array}{l}\text { Isogenic potApotBpotCpotD } \\
\text { (sak_1196,sak_1195,sak_1194 } \\
\text { and sak_1193) deletion mutant } \\
\text { of A909 }\end{array}$ & This study \\
\hline \multicolumn{3}{|l|}{ Plamids } \\
\hline pG+host $1^{\text {TS }}$ & $\begin{array}{l}\text { Replication-thermosensitive } \\
\text { shuttle plasmid, Ery }{ }^{\mathrm{R}}\end{array}$ & {$[48]$} \\
\hline
\end{tabular}

pastries and seafood products [38]. Such ability to survive in many different environments indicates its large capability for adaptation. As polyamines are involved in the resistance mechanism of several bacterial species to environmental stress, they could be involved in the substantial ability for adaptation of $S$. agalactiae. However, the physiological role of polyamines and the phenotypic traits given by the PotABCD transporter have not yet been studied in S. agalactiae.

In the genome of all Streptococcus species, a gene called murB, which encodes an enzyme implicated in peptidoglycan biosynthesis, is localized upstream of the potABCD operon [19]. We previously identified the transcriptional promoter of $m u r B$ in the folK-murB intergenic region of S. agalactiae. We also localized another transcriptional promoter in the upstream folK gene and we showed that genes involved in folate biosynthesis are co-transcribed with murB. This co-transcription could be necessary to synchronize two processes of cell wall synthesis, as it was postulated that a folic acid-mediated reaction might be involved in cell wall synthesis $[39,40]$. In some $S$. agalactiae strains, the mobile element IS 1548 is inserted in the folK-murB intergenic region. The presence of this insertion sequence prevents the co-transcription of $m u r B$ with genes of the folate pathway. However, as IS1548 brings an additional promoter able to initiate murB transcription, the insertion of IS1548 results in a minor negative modulation of the expression of $m u r B$ [40]. In S. pneumoniae and S. suis, it was demonstrated that $\operatorname{mur} B$ is co-transcribed with pot $A B C D$, which suggests also a relationship between polyamine transport and peptidoglycan biosynthesis in streptococci $[19,41]$. Polyamines were described to be components of the peptidoglycan. In $S$. pneumoniae, putrescine can substitute for choline, which is involved in peptidoglycan synthesis and hydrolysis [41]. In S. suis, peptidoglycan synthesis and separation of daughter cells during cell division cannot be completed without the presence of polyamines [19]. In Gram-negative bacteria, spermidine, putrescine and cadaverine are also considered as constituents of the peptidoglycan, since they play a significant role in maintaining cell shape and integrity of the cell surface structure $[42,43]$. In $S$. agalactiae, the clc gene is located downstream of the pot $A B C D$ genes. The $\operatorname{mur} B$, pot $A B C D$ and $c l c$ genes are all transcribed in the same direction. The $c l c$ gene is predicted to code a $\mathrm{Cl}^{-} / \mathrm{H}^{+}$antiporter [27]. $\mathrm{Cl}^{-} / \mathrm{H}^{+}$antiporters found in $E$. coli promote proton expulsion and were described to be highly induced under acid stress [44]. The presence of $c l c$ downstream of pot $A B C D$ is noteworthy since, as discussed above, polyamines are involved in the resistance of some bacteria to acidic stress.

In this study, we first analysed the genome of $S$. agalactiae strains available at the National Center for Biotechnology Information (NCBI) database to look for the presence of genes encoding enzymes involved in known spermine, spermidine and putrescine biosynthesis pathways. Similarly, the prevalence of the pot $A B C D$ operon in S. agalactiae strains was evaluated by BLAST analysis of completely sequenced genomes. The polyamine biosynthetic and transport capability of $S$. agalactiae was tested by TLC analyses of the intracellular polyamine content of bacteria grown in the absence or in the presence of polyamines. We then examined the transcription pattern of the pot $A B C D$ region and analysed the expression of the pot operon in response to polyamines and various stress conditions. The influence of polyamines on the growth and on the survival of $S$. agalactiae was finally determined.

\section{METHODS}

\section{Plasmids, bacterial strains and growth conditions}

The plasmids and bacterial strains used in this study are listed in Table 1. E. coli strains were cultured in liquid LB medium (MP Biomedicals; Cat. no. 3002022) or on LB-agar plates (1.5\% agar). Liquid cultures of E. coli were agitated at 200 r.p.m. at $37^{\circ} \mathrm{C}$. S. agalactiae strains were routinely grown on $5 \%$ horse blood trypticase soy (TSH) agar plates $(1.5 \%$ agar) (bioMérieux; Cat no. 43061) or on Todd Hewitt (TH) agar plates (BD Bacto; Cat. no. 249240). Liquid cultures of S. agalactiae were performed at $37^{\circ} \mathrm{C}$ without agitation in TH broth (BD Bacto; Cat. no. 249240) adjusted to pH 7.4 with $\mathrm{HCl}$. For the maintenance of $\mathrm{pG}+$ hostl derivatives, $E$. coli and $S$. agalactiae strains were grown with erythromycin $\left(150 \mu \mathrm{g} \mathrm{ml}^{-1}\right.$ for E. coli or $10 \mu \mathrm{g} \mathrm{ml}^{-1}$ for S. agalactiae $)$.

\section{Liquid chemically defined media for growth of $S$. agalactiae}

The liquid chemically defined medium used to grow $S$. agalactiae (CDM) contains $8.3 \mathrm{~g} \mathrm{l}^{-1}$ Dulbecco's modified Eagle medium base (catalogue no. D5030; Sigma-Aldrich), $1 \times$ BME vitamins, $74 \mu \mathrm{M}$ adenine, $89.2 \mu \mathrm{M}$ uracil, $65.7 \mu \mathrm{M}$ xanthine, $66.2 \mu \mathrm{M}$ guanine, $1123.5 \mu \mathrm{M}$ D,L-alanine, $757 \mu \mathrm{M} \mathrm{L}$-asparagine, $1127 \mu \mathrm{M}$ L-aspartic acid, $684.5 \mu \mathrm{M}$ L-glutamine, $1019.5 \mu \mathrm{M}$ L-glutamic acid, $868.6 \mu \mathrm{M}$ L-proline, $734.9 \mu \mathrm{M}$ L-tryptophan, $4125.4 \mu \mathrm{M}$ L-cysteine, $12 \mu \mathrm{M}$ lipoic acid, $1 \mu \mathrm{M}$ pyruvate, $17.4 \mu \mathrm{M} \mathrm{ZnSO}_{4} .7 \mathrm{H}_{2} \mathrm{O}$, 
$10.5 \mu \mathrm{M} \mathrm{CoCl} \cdot \mathrm{H}_{2} \mathrm{O}, 0.4 \mu \mathrm{M} \mathrm{CuSO}_{4} \cdot 5 \mathrm{H}_{2} \mathrm{O}$ and $55 \mathrm{mM}$ D-glucose. This medium was finally adjusted to $\mathrm{pH} 7.4$ with $\mathrm{HCl}$. For some experiments, CDM was buffered at $\mathrm{pH} 7.4$ with $100 \mathrm{mM}$ HEPES (Fisher Bioreagents; cat. no. BP310100 ), to pH 5.5 with $100 \mathrm{mM}$ MES (ACROS Organics; code no. 172591000) or $\mathrm{pH} 4.0$ by the addition of $33.5 \mathrm{mM}$ sodium citrate dihydrate and $66.5 \mathrm{mM}$ citric acid. Final adjustments of the $\mathrm{pH}$ were made with citric acid or $\mathrm{HCl}$. Spermidine (ACROS Organics; Cat. No. AC132740050), putrescine (ACROS Organics; Cat. No. AC132750050) or spermine (ACROS Organics; Cat. No. AC112120250) were also added for some experiments.

\section{Measurement of bacterial growth}

For measuring bacterial growth in chemically defined medium, S. agalactiae strains were first cultured in $\mathrm{TH}$ broth at $\mathrm{pH} 7.4$ (without agitation) to the stationary phase of growth. These cultures were centrifuged and washed in non-buffered $\mathrm{CDM}$ at $\mathrm{pH}$ 7.4. They were then suspended to an $\mathrm{OD}_{600 \mathrm{~nm}}$ of 0.005 in the same medium and grown overnight at $37^{\circ} \mathrm{C}$, without agitation. These last cultures were finally diluted to an $\mathrm{OD}_{600 \mathrm{~nm}}$ of 0.05 in CDM adjusted to the $\mathrm{pH}$ and polyamine concentration of interest. These last cultures were incubated at $37^{\circ} \mathrm{C}$ for $16 \mathrm{~h}$ in microtitre plates (Greiner Bio-One; Cellstar) (300 $\mu$ culture volume per well) in an Eon thermoregulated spectrophotometer plate reader (BioTek Instruments). The $\mathrm{OD}_{600 \mathrm{~nm}}$ was measured every hour after double orbital shaking of the plate for $5 \mathrm{~s}$. The reported $\mathrm{OD}_{600}$ $\mathrm{nm}$ is the average OD of three wells inoculated with the same ${ }_{\mathrm{nm}}^{\mathrm{nm}}$ culture. Three independent experiments were realized for all strains and for all tested conditions.

\section{Bioinformatics analysis}

To identify S. agalactiae homologues of enzymes involved in the known putrescine, spermidine and spermine biosynthesis pathways, the non-redundant protein sequences of S. agalactiae, available at the NCBI database on the 5 July 2019 , were blasted with the amino acid sequence of the constitutive (SpeC) and inducible (SpeF) ornithine decarboxylase, the inducible arginine decarboxylase (AdiA) and the L-methionine adenosyltransferase (MetK) of E. coli (accession nos. NP_417440, NP_415220, NP_418541.2 and NP_417417), with the arginine decarboxylase (accession no. ABJ55263.1), the agmatine deiminase (accession no. $\mathrm{ABJ54341.1)}$, the N-carbamoyl putrescine amidohydrolase (accession no. ABJ55190), the carboxyspermidine dehydrogenase (accession no. ABJ55062.1), the carboxyspermidine decarboxylase (accession no. ABJ53691) and the spermidine synthase (accession no. ABJ54021.1) of S. pneumoniae, with the $S$-adenosyl-methionine decarboxylase (SpeD), the aspartate kinase III, the aspartate- $\beta$-semialdehyde dehydrogenease, the agmatinase (SpeB) and the spermine synthase of Bacillus subtilis (accession nos. NC_00964.3, NP_388261.1, NP_389557.1, NP_391629 and QBJ65844, respectively), as well as with the agmatine aminopropyltransferase and the aminopropylagmatine ureohydrolase of Thermus thermophilus (accession nos. WP_011172918 and
WP_011228458.1. The sequences of S. agalactiae genomes available as whole genome contigs or as complete genome sequences at the NCBI database were also blasted with the nucleotide coding sequences of the $S$. pneumoniae enzymes mentioned above.

To identify $\sigma^{70}$ transcriptional promoters, the sequence of the intergenic regions between folK and $m u r B$, and potD and $c l c$, of strain A909 were analysed with the BProm software from the SoftBerry suite (http:// www.softberry.com/berry.phtml? topic $=$ bprom \&group $=$ programs $\&$ subgroup $=g$ findb).

Rho-independent transcriptional terminators were searched with the Arnold program (http://rssf.i2bc.paris-saclay.fr/ toolbox/arnold/) with the sequences of all intergenic regions and with the entire coding sequence of $\operatorname{mur} B$, pot $A$, potB, pot $C$, pot $D, c l c$ and araC.

Prediction of transmembrane helices in PotB and PotC was performed by the TMHMM Server of the Center for Biological Sequence Analysis at the Technical University of Denmark (http://www.cbs.dtu.dk/services/TMHMM/).

The presence of a signal peptide and the location of its cleavage sites in PotD was predicted with the SignalP 5.0 server (http:// www.cbs.dtu.dk/services/SignalP/).

The synteny of the folK-murB-potABCD-clc region in streptococcal species was compared via the SyntTax web server (https://archaea.i2bc.paris-saclay.fr/synttax/).

\section{Survival of S. agalactiae to peroxidase-induced oxidative and acidic stress}

To measure the ability of $S$. agalactiae strains to survive in $\mathrm{CDM}$ at $\mathrm{pH} 4.0$, the bacteria were cultured at $37^{\circ} \mathrm{C}$ (without agitation) in non-buffered $\mathrm{TH}$ broth at $\mathrm{pH} 7.4$ to the beginning of the stationary phase of growth. This culture was then centrifuged, washed with non-buffered $\mathrm{CDM}$ at $\mathrm{pH}$ 7.4, and suspended to an $\mathrm{OD}_{600 \mathrm{~nm}}$ of $0.005 \mathrm{in} 40 \mathrm{ml}$ of the same medium. After an overnight incubation at $37^{\circ} \mathrm{C}$ without agitation, $10 \mathrm{ml}$ aliquots of this culture were transferred to Falcon tubes, which were centrifuged for $5 \mathrm{~min}$ at $5000 \mathrm{~g}$. Bacterial pellets were suspended in either $1 \mathrm{ml}$ CDM buffered at $\mathrm{pH} 4.0$ with a $100 \mathrm{mM}$ mix of $\mathrm{Na}$ citrate and citric acid without the presence of polyamines or in $1 \mathrm{ml}$ of the same medium containing $1 \mathrm{mM}$ spermidine, spermine or putrescine. These suspensions were then incubated at $37^{\circ} \mathrm{C}$ (without agitation) for $6 \mathrm{~h}$. Viable cell counts of the bacteria were performed immediately after suspension of the pellets $\left(t_{0}\right)$ and at suitable time intervals thereafter. To this end, serial dilutions were performed in TH broth at $\mathrm{pH}$ 7.4. Then $100 \mu \mathrm{l}$ of each of these dilutions was immediately spread three times onto TH agar plates, which were incubated at $37^{\circ} \mathrm{C}$ for $24 \mathrm{~h}$. All survival experiments were performed at least three times. Results are expressed as the percentage of survivors [(number of viable bacteria at the tested condition divided by the number of viable bacteria at $\left.\mathrm{t}_{0}\right) \times 100$ ]

To compare the sensitivity of the pot $A B C D$ mutant and the wild-type strains to peroxidase-induced oxidative stress, $S$. 
agalactiae strains were grown to an $\mathrm{OD}_{600 \mathrm{~nm}}$ of $0.6 \mathrm{in} \mathrm{TH}$ broth and then exposed to different concentrations of $\mathrm{H}_{2} \mathrm{O}_{2}$ $(1,5$ or $20 \mathrm{mM})$.

To test if polyamines are involved in the survival of $S$. agalactiae strains submitted to peroxidase-induced oxidative stress, $S$. agalactiae cultures were grown in TH broth to the beginning of the stationary phase. Each culture was then centrifuged, washed with non-buffered CDM at $\mathrm{pH}$ 7.4 , and suspended to an $\mathrm{OD}_{600 \mathrm{~nm}}$ of 0.005 in $10 \mathrm{ml}$ of the same medium and grown overnight at $37^{\circ} \mathrm{C}$ without agitation. These last cultures were finally diluted to an $\mathrm{OD}_{600 \mathrm{~nm}}$ of 0.05 in $\mathrm{CDM}$ at $\mathrm{pH} 7.4$, and grown until an $\mathrm{OD}_{600 \mathrm{~nm}}$ of 0.6 (exponential phase). Bacterial cultures ( $10 \mathrm{ml}$ samples) were then harvested and exposed to peroxidase-induced oxidative stress after suspension in the same volume of CDM containing either $5 \mathrm{mM} \mathrm{H}_{2} \mathrm{O}_{2}, 5 \mathrm{mM} \mathrm{H}_{2} \mathrm{O}_{2}$ and $1 \mathrm{mM}$ spermidine, $5 \mathrm{mM} \mathrm{H}_{2} \mathrm{O}_{2}$ and $1 \mathrm{mM}$ spermine, or $5 \mathrm{mM} \mathrm{H}_{2} \mathrm{O}_{2}$ and $1 \mathrm{mM}$ putrescine. Viable cell counts of the bacteria were performed immediately after the suspension of the pellets $\left(\mathrm{t}_{0}\right)$ and at suitable time intervals thereafter. To this end, serial dilutions were performed in $\mathrm{TH}$ broth at $\mathrm{pH}$ 7.4. Then $100 \mu \mathrm{l}$ of each of these dilutions was immediately spread onto $\mathrm{TH}$ agar plates, which were incubated at $37^{\circ} \mathrm{C}$ for $24 \mathrm{~h}$. All survival experiments were performed at least three times. The results are expressed as the percentage of survivors [(number of viable bacteria at the tested condition divided by the number of viable bacteria at $\left.t_{0}\right) \times 100$ ]

\section{Expression of potABCD during acidic and peroxidase-induced oxidative stress}

To quantify the expression of the pot $A B C D$ operon during acidic stress, strain A909 was grown in Falcon tubes containing $10 \mathrm{ml} \mathrm{TH}$ broth to the beginning of the stationary phase of growth. Each culture was then centrifuged, washed with non-buffered $\mathrm{CDM}$ at $\mathrm{pH} 7.4$, suspended to an $\mathrm{OD}_{600 \mathrm{~nm}}$ of $0.005 \mathrm{in} 10 \mathrm{ml}$ of the same medium, and grown overnight at $37^{\circ} \mathrm{C}$ without agitation. These last cultures were finally diluted to an $\mathrm{OD}_{600 \mathrm{~nm}}$ of 0.05 in $\mathrm{CDM}$ at $\mathrm{pH} 7.4$, and grown to an $\mathrm{OD}_{600 \mathrm{~mm}}$ of 0.6 (exponential phase). Bacterial cells ( $10 \mathrm{ml}$ samples) were then harvested, centrifuged, and suspended either in $10 \mathrm{ml}$ CDM buffered at pH 5.5 with $100 \mathrm{mM}$ MES or in CDM buffered at $\mathrm{pH} 4.0$ with a mix of $\mathrm{Na}$ citrate and citric acid. These media were either supplemented or not with $1 \mathrm{mM}$ spermidine, spermine or putrescine. The bacteria were exposed to the acidic stress for $30 \mathrm{~min}$. A control culture grown at $\mathrm{pH} 7.4$ in $\mathrm{CDM}$ without acidic stress was treated similarly. All cultures were then centrifuged at $5000 \mathrm{~g}$. Bacterial pellets were collected and then stored at $-80^{\circ} \mathrm{C}$ until RNA extraction. This experiment was repeated three times from three independent cultures.

To determine the expression of potA during peroxidaseinduced oxidative stress by quantitative reverse transcriptase (qRT-PCR), the same treatment was performed as described for the peroxidase-induced oxidative stress survival assay. Thus, the wild-type cultures were collected after either 20 or $60 \mathrm{~min}$ of exposure to $5 \mathrm{mM} \mathrm{H}_{2} \mathrm{O}_{2}$, in the absence and in the presence of each type of polyamine. A control culture grown at $\mathrm{pH} 7.4$ in CDM without any stress was always collected at the same time. Cultures were then centrifuged at $5000 \mathrm{~g}$. Bacterial pellets were collected and then stored at $-80^{\circ} \mathrm{C}$ until RNA extraction. This experiment was repeated three times from three independent cultures.

\section{Nucleic acid manipulations}

Standard nucleic acid manipulation techniques were carried out as described previously [45]. S. agalactiae genomic DNA and RNA purifications were performed as previously described [40]. Plasmids were purified from E. coli with a NucleoSpin Plasmid kit (Macherey-Nagel), according to the manufacturer's instructions. Nucleic acid concentrations were measured with a NanoDrop Lite Spectrophotomer (Thermo Scientific). The ratio of absorbance at 260 and $280 \mathrm{~nm}$ was used to check the purity of nucleic acids. Bacteria were transformed by electroporation with the Micropulser apparatus (Bio-Rad) and the Ec2 conditions $(2.5 \mathrm{kV})$, as described by Dower for E. coli and by Ricci for S. agalactiae $[46,47]$.

\section{Amplification of nucleic sequences by PCR, by RT- PCR and by qRT-PCR}

PCR was carried out with the Applied Biosystem 2720 Thermal cycler using Q5 High-Fidelity DNA polymerase (New England Biolab) for cloning or sequencing or OneTaq polymerase (New England Biolab) for analytical PCR. For cloning or sequencing, the resulting PCR fragments were further purified with a NucleoSpin Gel and PCR clean-up kit (Macherey-Nagel) or with a NucleoSEQ kit (MachereyNagel), according to the manufacturer's instructions. The oligonucleotides (Sigma-Aldrich) used in this study are listed in Table 2.

For RT-PCR and qRT-PCR, the RNAs were reverse transcribed as previously described [40]. For RT-PCR, cDNAs were amplified by PCR with appropriate primers (Fig. 2a, Table 2), as described above for PCR amplification of DNA. Control RT-PCRs, omitting reverse transcriptase, were performed to check for DNA contamination of the RNA preparation.

For qRT-PCR, primers were selected with Primer3web software (https://bioinfo.ut.ee/primer3/) in order to generate 100 to $300 \mathrm{bp}$ amplicons (Table 2). qRT-PCRs were performed in a $20 \mu \mathrm{l}$ reaction volume containing $40 \mathrm{ng}$ of cDNA, $0.5 \mu \mathrm{l}$ of gene-specific primers $(10 \mu \mathrm{M})$ and $7.5 \mu \mathrm{l}$ LightCycler 480 SYBR Green I Master $2 \times$ (Roche, code no. 04707516001). PCR amplification, detection and analysis were realized with the Bio-Rad CFX Connect Real-Time PCR detection system and Bio-Rad CFX Maestro software. PCR conditions included an initial denaturation step at $95^{\circ} \mathrm{C}$ for $5 \mathrm{~min}$, followed by a 40 -cycle amplification $\left(95^{\circ} \mathrm{C}\right.$ for $10 \mathrm{~s}, 60^{\circ} \mathrm{C}$ for $20 \mathrm{~s}$ and $72^{\circ} \mathrm{C}$ for $\left.20 \mathrm{~s}\right)$. The specificity of the amplified product and the absence of primer dimer formation were verified by generating a melting curve $\left(65-98^{\circ} \mathrm{C}\right.$, continuous increase). The cycle threshold 
Table 2. Primers used in this study

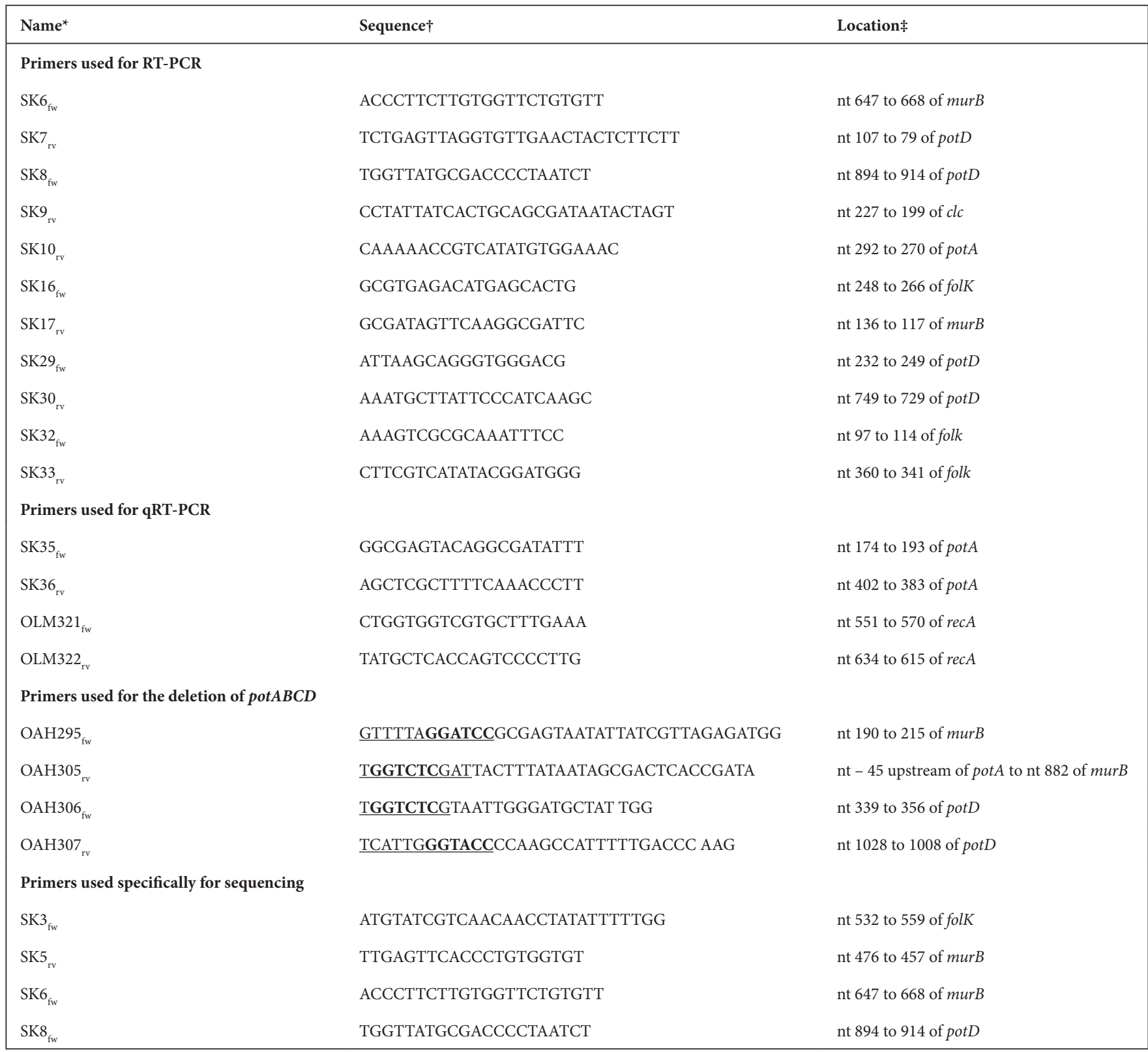

${ }^{*} f w$, forward primer; rv, reverse primer.

†Tails containing a restriction site (in bold) are underlined.

$\ddagger$ Nucleotide (nt) position with respect to the first coding nt of the gene of interest or to a polylinker restriction site.

(Ct) was defined for each sample. Expression levels of the tested genes were normalized using the $r e c A$ gene (primers OLM321 and OLM322) of S. agalactiae. Transcript levels of $r e c A$ did not vary under our experimental conditions (Table 2). The fold change in the transcript level was calculated using the following equations: $\Delta \mathrm{Ct}=\mathrm{Ct}$ (target gene) - Ct (recA gene); $\Delta \Delta \mathrm{Ct}=\Delta \mathrm{Ct}$ (reference condition) $-\Delta \mathrm{Ct}$ (test condition); relative quantification $(\mathrm{RQ})=2^{-\Delta \Delta \mathrm{Ct}}$. Each assay was performed in triplicate and repeated with at least three independent RNA samples.

\section{DNA sequencing}

PCR products were sequenced on both strands using the Big Dye Terminator v3.1 cycle sequencing kit from Applied Biosystems and the ABI Prism 310 Genetic Analyzer.

\section{Construction of potABCD deletion mutant}

S. agalactiae A909 $\triangle$ pot $A B C D$ is a non-polar mutant of strain A909 deleted by allelic exchange of a DNA region beginning five nucleotides after the stop of murB and ending 338 nucleotides after the start of potD. Upstream and 
(a)

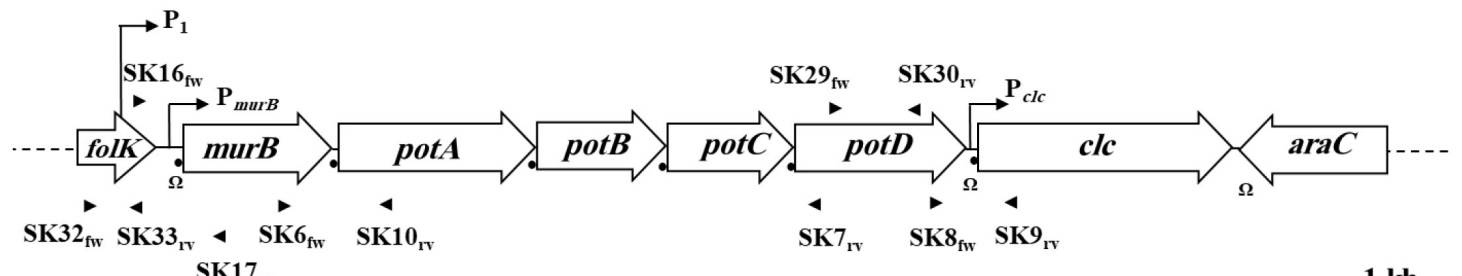

(b)

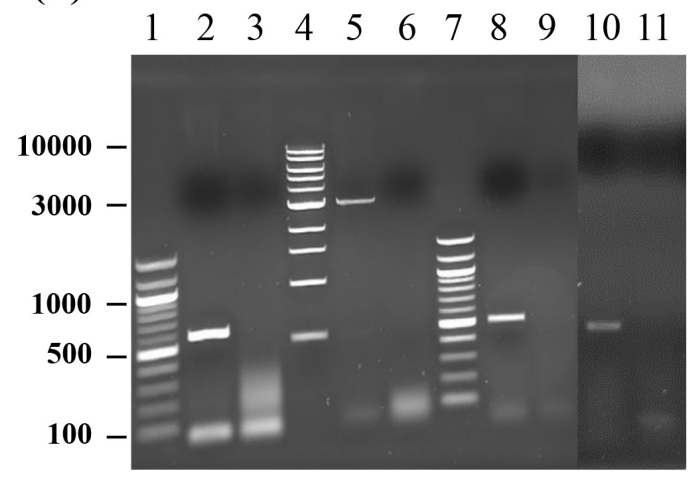

(c)

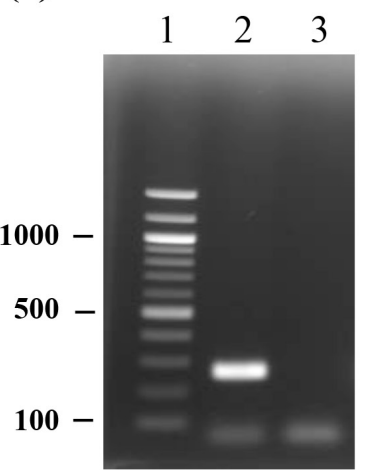

(d)

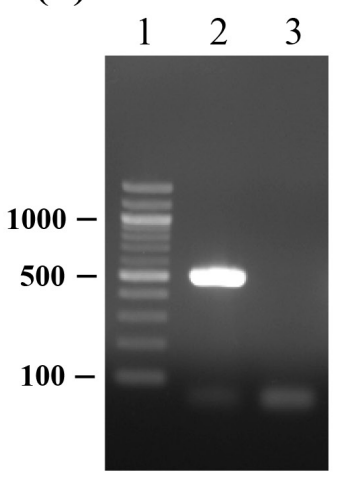

Fig. 2. Transcriptional analysis of the potABCD region of Streptococcus agalactiae A909. Putative transcriptional promoters ( $\overrightarrow{)}$ and rhoindependent terminators $(\Omega)$ were identified in silico by the BPROM and the Arnold software, respectively. ORFs (open arrows), ribosome binding sites ( ) and primers $(-)$ used in RT-PCR experiments are indicated in the schematic representation of the folK-araC region of S. agalactiae (a). Co-transcripts between murB and potA (lane $2 \mathrm{~b}$ ), between murB and potD (lane 5b), between potD and clc (lane $8 \mathrm{~b})$, and between folK and murB (lane 10b) were revealed by RT-PCR performed with primers annealing in murB and potA (SK6 $\left.6_{\mathrm{fw}} / \mathrm{SK} 10_{\mathrm{rv}}\right)$, in $m$ m $B$

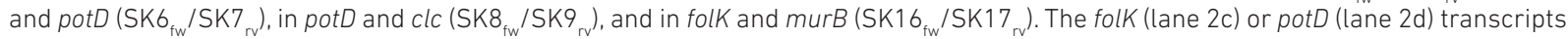
were revealed by RT-PCR performed with primers annealing in folK (SK32 $\mathrm{f}_{\mathrm{w}} / \mathrm{SK} 33_{\mathrm{rv}}$ ) or in potD (SK29 $\mathrm{fw} / \mathrm{SK} 30_{\mathrm{rv}}$ ), respectively. RT-PCRs were performed in the absence of reverse transcriptase to check for DNA contamination (lanes 3b, 6b, 9b, 11b, 3c and 3d). Amplification products were electrophoresed in a $1 \%$ agarose gel containing ethidium bromide and visualized under UV light ( 260 nm). Molecular weight markers (Quick-Load Purple, 100 bp and 1 kb DNA Ladder; New England Biolabs) of the indicated sizes are in lanes 1b, 7b, 1c or $1 \mathrm{~d}$ and $4 \mathrm{~b}$, respectively.

downstream regions of the deleted region were amplified by PCR with primers $\mathrm{OAH} 295_{\mathrm{fw}} / \mathrm{OAH} 305_{\mathrm{rv}}$ and $\mathrm{OAH} 306_{\mathrm{fw}} /$ $\mathrm{OAH} 307_{\mathrm{rv}}$, respectively. These amplified fragments were cut by $B s a \mathrm{I}$, and a recombination cassette, consisting of a fusion between these two regions, was obtained by splicing-by-overlap-extension PCR with primers OAH295 and $\mathrm{OAH}_{30} 7_{\mathrm{rv}}$ (Table 2). To carry out chromosomal gene inactivation, the overlap-extension fragment was hydrolysed by BamHI and KpnI, and cloned into the BamHI/KpnI sites of the thermosensitive shuttle plasmid pG +host1 [48]. The recombinant plasmid was electroporated in E. coli for amplification, purified and finally electroporated in strain A909. Allelic exchange was performed as described by Biswas [48]. Deletion of the pot $A B C D$ region of $S$. agalactiae A909 was confirmed by sequencing with primers $\mathrm{SK} 3_{\mathrm{fw}}$, SK5 ${ }_{\mathrm{rv}}, \mathrm{SK} 6_{\mathrm{fw}}$ and SK8 $8_{\mathrm{fw}}$ (Table 2).

\section{Determination of the intracellular polyamine content}

Intracellular polyamine content was determined as described in the literature $[49,50]$. In brief, aliquots from bacterial cultures were pelleted. Then, $200 \mathrm{mg}$ (wet weight) of bacteria was washed four times with PBS and suspended in $1 \mathrm{ml}$ of $0.2 \mathrm{M}$ perchloric acid. They were subsequently disrupted by sonication and centrifuged for $10 \mathrm{~min}$ at 12 $000 \mathrm{~g}\left(4^{\circ} \mathrm{C}\right)$. The supernatant was collected and $200 \mu \mathrm{l}$ of the extract was dansylated by the addition of $0.4 \mathrm{ml}$ of a solution of dansylchloride ( $30 \mathrm{mg}$ dansylchloride $\mathrm{ml}^{-1}$ acetone) and $50 \mathrm{mg} \mathrm{Na} \mathrm{CO}_{3} \cdot 10 \mathrm{H}_{2} 0$. After incubation for $16 \mathrm{~h}$ in the dark (ambient temperature), $0.1 \mathrm{ml}$ of a proline solution was added $\left(100 \mathrm{mg} \mathrm{m}^{-1} \mathrm{H}_{2} \mathrm{O}\right.$ Milli- $\left.\mathrm{Q}^{\mathrm{R}}\right)$ and the extract was incubated again for $30 \mathrm{~min}$. Dansylated polyamines were extracted with $700 \mu \mathrm{l}$ of toluene. Dansylated toluene extracts $(40 \mu \mathrm{l})$ were then determinated by TLC on silica gel $60 \mathrm{G}$ plates (Merck). The dansylated polyamines were separated by development in ethylacetate/cyclohexane (2:3, $\mathrm{v} / \mathrm{v})$ followed immediately by spraying the TLC plate with triethanolamine/cyclohexane $(1: 4, \mathrm{v} / \mathrm{v})$ to enhance and stabilize fluorescence. Similarly, $200 \mu \mathrm{l}$ of a $1 \mathrm{mM}$ solution of spermine, spermidine or putrescine in Milli- $\mathrm{Q}^{\mathrm{R}}$ water was dansylated, extracted with toluene and $40 \mu$ of each extract was assessed by TLC. After drying, spots were visualized under Wood light and photographed. 


\section{Statistical analyses}

Data are presented as the mean \pm SD for three independent experiments. An unpaired Student's $t$-test was used to determine the significance of the differences between means [51].

\section{RESULTS AND DISCUSSION}

\section{The putrescine, spermidine and spermine biosynthesis pathways are not present in $S$. agalactiae}

We searched, by BLASTP analysis, if $S$. agalactiae possesses homologues of enzymes involved in the known putrescine, spermidine and spermine biosynthesis pathways (Fig. 1). Only three enzymes (aspartate kinase, aspartate $\beta$ semialdehyde dehydrogenase and L-methionine adenosyl transferase) involved in one or the other first steps of spermidine or spermine biosynthesis were encoded by all strains of $S$. agalactiae. These three enzymes are also involved in the biosynthesis of several amino acids and are essential for S. agalactiae (e.g. SAK_0414, SAK_0954 and SAK_1141 in https://www.genome.jp/kegg-bin/show_organism?org= sak). One (DK-PW-092) of the 1018 analysed strains also encodes an agmatine deiminase (gene WA34_16675) and an $\mathrm{N}$-carbamoylputrescine amidohydrolase (gene WA34_ 16685). In the genus Streptococcus, the presence of polyamine biosynthesis pathways was searched by others in three other species. All the genomes of $S$. pneumoniae and the two completely sequenced genomes of Streptococcus oralis encode the enzymes necessary for the polyamine biosynthesis pathways IIp, Is and IIs (Fig. 1). However, these three pathways were found in only two of all the 30 completely sequenced genomes of $S$. suis and in two of the three completely sequenced genomes of $S$. mitis $[11,19]$. It is not known if the need of certain streptococcal species for a polyamine biosynthesis pathway reflects their lifestyle and their ability to survive at certain stages in polyamine-free environments.

As homologues of most of the enzymes involved in the known biosynthesis pathways of putrescine, spermidine and spermine are absent in $S$. agalactiae, this bacterium should not be able to synthesize these polyamines, and presumably acquired them from the environment. We verified this hypothesis by TLC analyses performed on the intracellular polyamine content of bacteria grown in the absence or in the presence of polyamines. Fig. 3(a) shows that $S$. agalactiae is unable to biosynthesize spermine, spermidine or putrescine (lane 1a), whereas it is able to strongly transport spermidine and spermine (lanes $2 \mathrm{a}$ and $3 a)$ and slightly transport putrescine (lane $4 a$, white arrow) at $\mathrm{pH}$ 7.4.

\section{Prevalence of the potABCD genes of $S$. agalactiae and characteristics of the transporter}

As almost all bacteria can import extracellular polyamines by the $A B C$ transporter pot $A B C D$, we searched the prevalence of the pot $A B C D$ genes in S. agalactiae strains. To that end,
BLASTN analyses with the nucleotide sequence of potABCD of strain A909 were performed in the non-redundant nucleotide collection of $S$. agalactiae sequences, available at the NCBI database. This operon is conserved in all the completely sequenced genomes of $S$. agalactiae (130 strains at the time of our analysis). We also screened this databank by TBLASTN with the Pot $\mathrm{A}, \operatorname{Pot} \mathrm{B}, \operatorname{Pot} \mathrm{C}$ and PotD protein sequences of strain A909. In 90.8, 93.1, 97.0 and $99.2 \%$ of these strains, the PotA, PotB, PotC or PotD sequences are identical to those of strain A909, respectively. The few non-identical PotA, PotB or PotC proteins were translated from nucleotide sequences of pseudogenes. Non-identical PotA proteins contain only one mismatch with respect to the sequence of strain A909. Seventeen per cent of these mismatches concern similar amino acids.

The amino acid sequence of PotA has the characteristic motifs of the nucleotide binding proteins [52]. It contains the two ATP/GTP binding site motifs Walker A and Walker B at positions 40-47 and 162-169, respectively. The characteristic ABC transporter family signature, with one mismatch, was also identified as correctly located (position 162-169) between the two Walker motifs. PotA also has at a correct location (position 192-197), the Linton and Higgins motif, containing at the fifth position the highly conserved histidine implicated in the function of the $\mathrm{ABC}$ transporters. PotB and PotC also have characteristic motifs of membrane spanning proteins of $\mathrm{ABC}$ transporters. PotB and PotC have $24 \%$ identical and $16 \%$ similar amino acids in common. Both of them are integral transmembrane proteins predicted to be composed of six transmembrane domains by the THMM server. PotB and PotC contain also the $\mathrm{ABC}$ transporter integral membrane type-1 domain (PS50928) at positions 57-259 and 58-246, respectively. The signalP server predicts the existence of a signal peptide (sec/SPI) in the substrate binding protein PotD, with a cleavage site between position 31 and 32. Substrate binding proteins of Gram-positive $\mathrm{ABC}$ transporters are generally lipoprotein [52]. However, no lipid attachment site could be identified in PotD. We also searched for the presence of other domains involved in the anchoring of proteins to the surface of Gram-positive bacteria: LPXTG sequences for binding to the peptidoglycan by a sortase or choline-binding domains for the attachment to choline residues of lipoteichoic acids. None of them could be identified in PotD. This protein may thus be anchored to the cytoplasmic membrane by an as yet unidentified mechanism. A similar situation was described for PotD of S. pneumoniae [53]. PotD of S. agalactiae possesses the bacterial spermidine/putrescine binding motif described by Shah and collaborators [54]. This binding fold is composed of two globular subdomains connected by a flexible hinge and bind their ligand in the cleft between these domains in a manner resembling a Venus flytrap [55].

\section{Transcriptional analysis of the potABCD region of $S$. agalactiae A909}

The pot $A B C D$ genes of $S$. agalactiae are transcribed in the same direction as the $f_{0}$ genes, $\operatorname{mur} B$ and $c l c$, suggesting that they are co-transcribed (Fig. 2a). Most of these genes are separated 
(a)

(b)

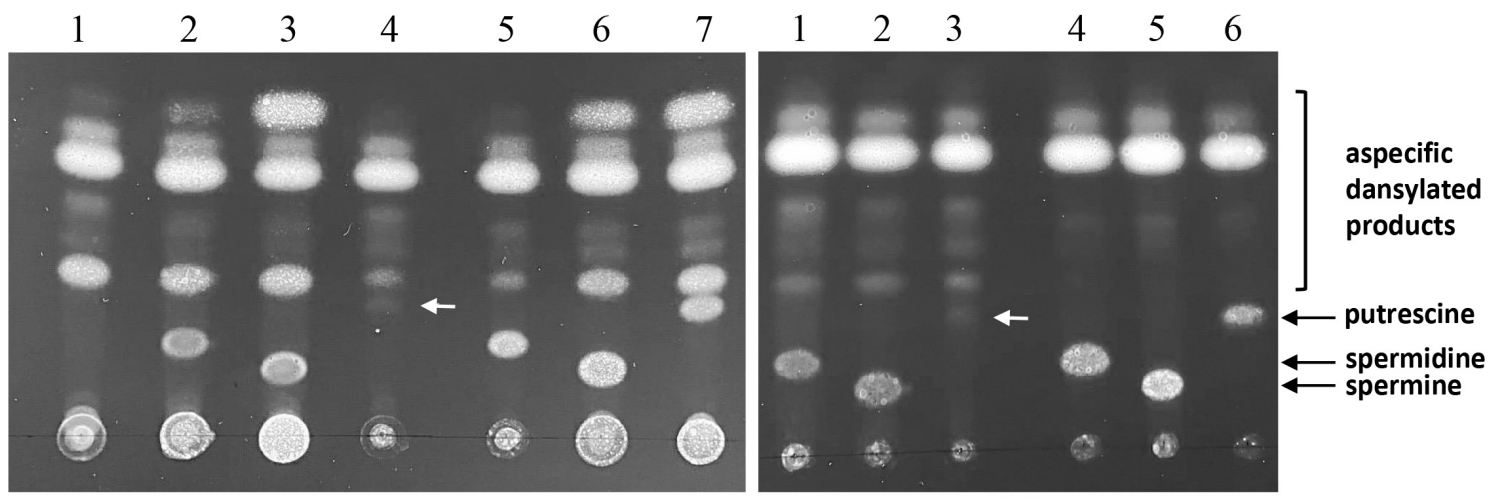

(c)

(d)

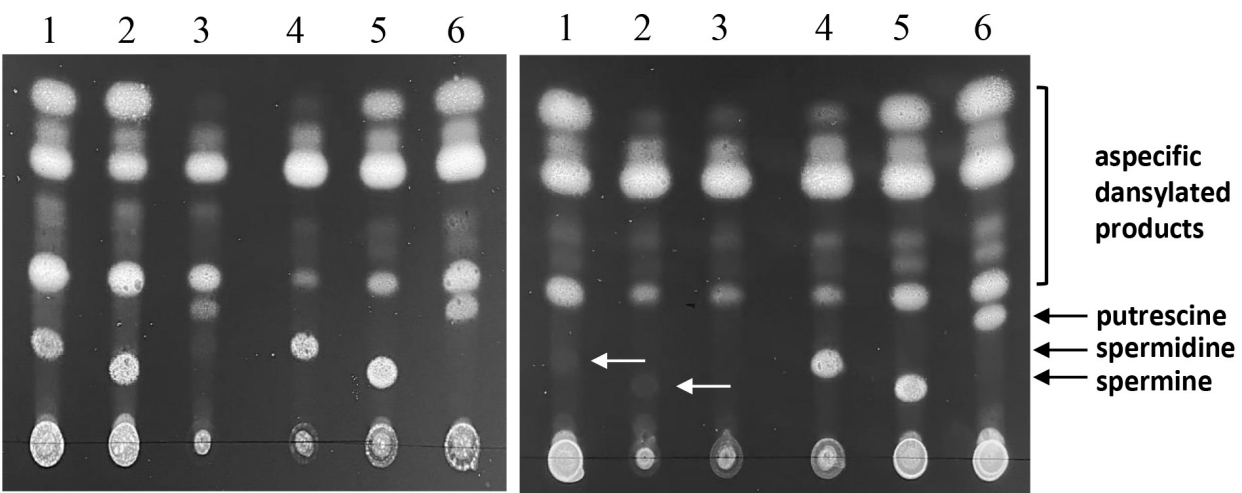

Fig. 3. Intracellular polyamine content of S. agalactiae. S. agalactiae wild-type strain (a and c) or $\triangle$ potABCD mutant (b and d) were grown either to the beginning of the stationary phase ( $a$ and b) or to an $\mathrm{OD}_{600 \mathrm{~nm}}$ of 0.6 (exponential growth phase, $c$ and d) in a chemically defined medium at pH 7.4 in the absence (lane 1a) and in the presence of $1 \mathrm{mM}$ spermidine (lanes 2a, 1b, 1c and 1d), 1 mM spermine (lanes 3a, $2 b, 2 c$ and 2D) or $1 \mathrm{mM}$ putrescine (lanes $4 \mathrm{a}, 3 \mathrm{~b}, 3 \mathrm{c}$ and $3 \mathrm{~d}$ ). In (c) and (d), bacteria were then exposed to $5 \mathrm{mM} \mathrm{H}_{2} \mathrm{O}_{2}$ for $60 \mathrm{~min}$ Bacterial extracts were dansylated, separated by TLC and photographed under Wood light. Dansylated standards of spermidine $(0.2 \mu \mathrm{g}$; lanes $5 \mathrm{a}$, $4 \mathrm{~b}, 4 \mathrm{c}$ and $4 \mathrm{~d})$, spermine $(0.2 \mu \mathrm{g}$; lanes $6 \mathrm{a}, 5 \mathrm{~b}, 5 \mathrm{c}$ and $5 \mathrm{~d})$ and putrescine $(0.1 \mu \mathrm{g}$; lanes $7 \mathrm{a}, 6 \mathrm{~b}, 6 \mathrm{c}$ and $6 \mathrm{~d}$ ) were deposited in each TLC plate. The white arrows indicate the intracellular presence of a small quantity of putrescine, spermine or spermidine.

by short intergenic sequences $(48,11$ and 2 nt between $\operatorname{mur} B$ and $\operatorname{pot} A, \operatorname{pot} A$ and $\operatorname{pot} B$, and $\operatorname{pot} C$ and $\operatorname{pot} D$, respectively) or possessed overlapping stop and start codons (potB and pot $C$ ). The folK-murB and potD-clc intergenic regions are 143 and $108 \mathrm{nt}$ long, respectively. Correctly conserved and positioned ribosome binding sites were identified upstream of all ORFs of the murB-clc region. We previously identified $\sigma^{70}$ transcriptional promoters inside the folK gene $\left(\mathrm{P}_{1}:-10\right.$ box, TTGAATTAT; -35 box, TAGAGA) and in the folK-murB intergenic region $\left(\mathrm{P}_{\text {mur }}\right.$ : -10 box, TGGTATAAT; -35 box, TCGTCA). Both of them were shown to be involved in the transcription of murB [40]. We here also identified putative $\sigma^{70}$ transcriptional promoters in the potD-clc intergenic region $\left(\mathrm{P}_{c l} ;-10\right.$ box: TGTTAAAAT, -35 box: TTCCTA). Potential Rho-independent transcriptional terminators were also identified in the folK-murB intergenic region (position -73 to -36 upstream of $\operatorname{mur} B ; \Delta G=-5.3 \mathrm{kcal}$ ), in the potD-clc intergenic region (position -104 to -62 upstream of $c l c ; \Delta G=-9.7 \mathrm{kcal}$ ), and downstream of $c l c$ (position +22 downstream of $c l c$ to nt
920 of $\operatorname{araC} ; \Delta G=-10.4 \mathrm{kcal})$. By RT-PCRs performed with reverse primers annealing either in pot $A$ or in potD $\left(\mathrm{SK}_{\mathrm{rv}}\right.$ or SK7 ${ }_{r v}$ Table 2, Fig. 2a), and a forward primer annealing in $m u r B$ ( $\mathrm{SK}_{\mathrm{fw}}$, Table 2, Fig. 2a), we here showed that murB is also co-transcribed with pot $A B C D$ (Fig. 2, lanes $2 \mathrm{~b}$ and $5 \mathrm{~b}$, respectively). Similarly, by using the SK9 reverse primer annealing in $c l c$ and the SK8 forward primer annealing in potD (Table 2, Fig. 2a), we showed that pot $D$ is co-transcribed with $c l c$ (Fig. 2, lane 8b). We previously showed that folK is co-transcribed with murB in strain SA87 [40]. By using the SK17 reverse primer annealing in $\operatorname{murB}$ and the SK16 forward primer annealing in folK (Table 2, Fig. 2a), we confirm this fact in strain A909 (Fig. 2, lane 10b). As co-transcription of folK and murB and of potD and clc were demonstrated, the role of the two hairpin structures as transcriptional terminators is questionable; these structures could perhaps be attenuators or binding sites for a regulator protein. It is of note that an attenuator structure was identified in the leader sequence of the potABCD operon of Haemophilus somnus 
(a)

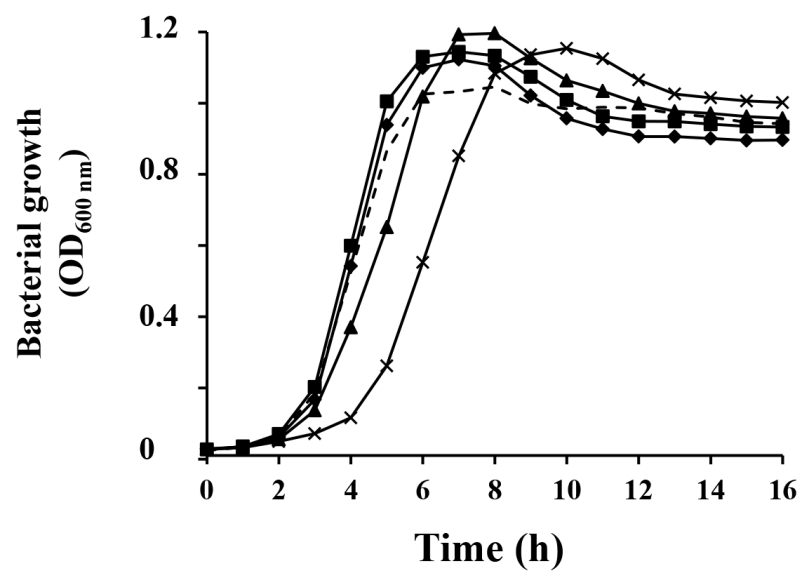

(b)

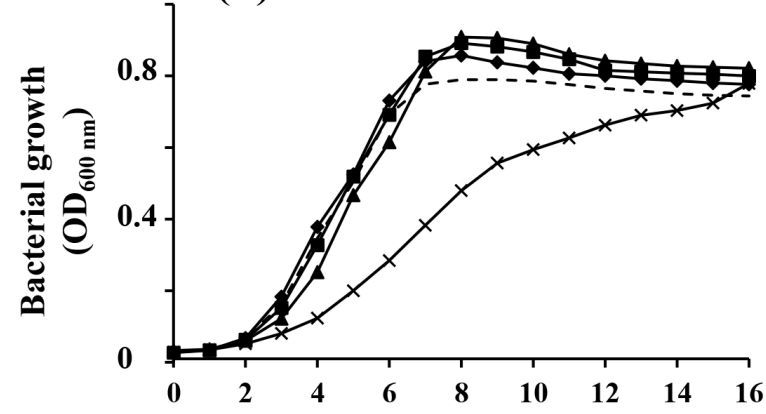

(c)

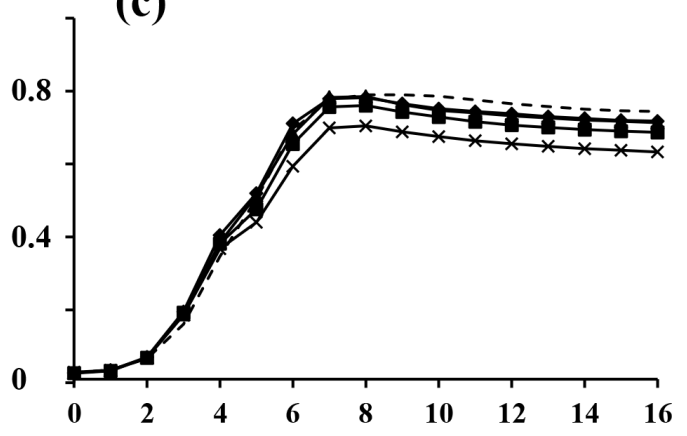

Time (h)

Fig. 4. Growth of S. agalactiae strain A909 in a chemically defined medium containing different concentrations of polyamines. S. agalactiae A909 was grown in a chemically defined medium buffered at pH 7.4 with $100 \mathrm{mM}$ HEPES in the absence of polyamines (---) or in the presence of various amounts (, $0.5 \mathrm{mM} ; \mathbf{\square}, 1 \mathrm{mM} ; \boldsymbol{\Delta}, 2 \mathrm{mM}$ and $\times, 5 \mathrm{mM}$ ) of spermidine (a), spermine (b) or putrescine (c). These cultures were incubated for $16 \mathrm{~h}$ at $37^{\circ} \mathrm{C}$ without agitation in microtitre plates $(300 \mu \mathrm{l}$ culture volume per well) in an Eon thermoregulated spectrophotometer plate reader. The $\mathrm{OD}_{600 \mathrm{~nm}}$ was measured every hour after double orbital shaking of the plate for $5 \mathrm{~s}$. The reported $\mathrm{OD}_{600 \mathrm{~nm}}$ is the average $\mathrm{OD}$ of three wells inoculated with the same culture. Three independent experiments were realized for all tested conditions. Standard deviations were always less than $10 \%$.

and of Pasteurella multocida [56]. We have thus compared the level of folK and of potD transcripts with those of folKmurB and potD-clc co-transcripts. To that end, RT-PCR was performed with reverse and forward primers annealing in folK (SK33 $3_{\mathrm{rv}}$ and SK32 $2_{\mathrm{fw}}$ ) and in potD (SK30 and SK29 $\left.9_{\mathrm{fw}}\right)$ (Table 2, Fig. 2a). Although this experiment is rather qualitative, amplification of the folK-murB (Fig. 2, lane 10b) and potD-clc (Fig. 2, lane 8b) co-transcripts is lower than that of folK (Fig. 2, lane 2c) or potD (Fig. 2, lane 2d), suggesting that the two hairpin structures arrest some of the upstream transcripts.

In conclusion, although the murB-pot $A B C D$ and the $c l c$ genes are also likely transcribed from their own $\mathrm{P}_{\text {mur }}$ and $\mathrm{P}_{c l c}$ promoters, the above results suggest that strain A909 synchronizes the biosynthesis of folate and peptidoglycan with the transport of a polyamine by PotABCD and with the resistance to acidic stress. An RNA-sequencing experiment conducted on strain NEM316 of S. agalactiae indicated that the $\mathrm{P}_{\text {mur } B}$ and the $\mathrm{P}_{c l c}$ promoters are functional and that the murB-pot $A B C D$ and $c l c$ transcripts are the major transcripts of the folK-clc region [57]. As the murB and pot $A B C D$ genes are also co-transcribed in S. pneumoniae and S. suis, it appears that it is particularly important for streptococcal species to coordinate these two processes involved in cell wall synthesis $[19,41]$. It is nevertheless of note that although the synteny of the murB and pot $A B C D$ genes is conserved in the entire genus Streptococcus, this is not the case for the complete folK-murB-pot $A B C D-c l c$ region. We compared the synteny of this region in the genomes of 676 streptococal strains representative of the genus Streptococcus and found that the entire folK-clc region is only conserved in species belonging to the pyogenic group (S. agalactiae, S. dysgalactiae subsp. equisimilis, $S$. equi subsp. equi, S. equi subsp. zooepidemicus, S. canis) and in non-pyogenic species of the Bovis group (S. equinus, $S$. gallolyticus, S. infantarius, S. lutetiensis, S. macedonicus, 
S. pasteurianus). In the non-pyogenic species S. suis, the synteny is only conserved from potA to clc. However, Liu and collaborators were not able to show a co-transcription between pot $A B C D$ and $c l c$ in this species [19] .

\section{No requirement of polyamines and of the PotABCD transporter for the growth of $\mathbf{S}$. agalactiae at pH $\mathbf{7 . 4}$}

Since $S$. agalactiae seems to be obligated to acquire polyamines from the environment, we tested if the PotABCD transporter and exogenous polyamines are required to sustain growth of this bacterium. We first grew $S$. agalactiae strain A909 in a chemically defined medium containing various concentrations of spermine, spermidine or putrescine. As polyamines are very basic components, this medium was buffered at $\mathrm{pH} 7.4$ with $100 \mathrm{mM}$ HEPES. Concentrations of spermidine or spermine of $1 \mathrm{mM}$ or below have only a very slight positive impact on the growth of $S$. agalactiae, but higher concentrations have an inhibitory impact (Fig. 4a, b). Putrescine has no effect on the growth of $S$. agalactiae until a concentration of $5 \mathrm{mM}$, when it becomes slightly inhibitory (Fig. 4c). We then constructed a deletion mutant of pot $A B C D$ to ensure that traces of polyamines eventually contaminating our minimal medium are not transported by the PotABCD transporter, thus allowing an identical growth of the wild-type strain in the presence or not of each of the polyamines tested. This assumption is, however, invalid as strains A909 and A909 $\triangle$ potABCD grow identically either in the rich TH medium or in the chemically defined medium in the absence of added polyamines (Fig. S1a, b, available in the online version of this article). No difference between the growth of the wild-type strain and of the pot $A B C D$ deletion mutant in a chemically defined medium containing $1 \mathrm{mM}$

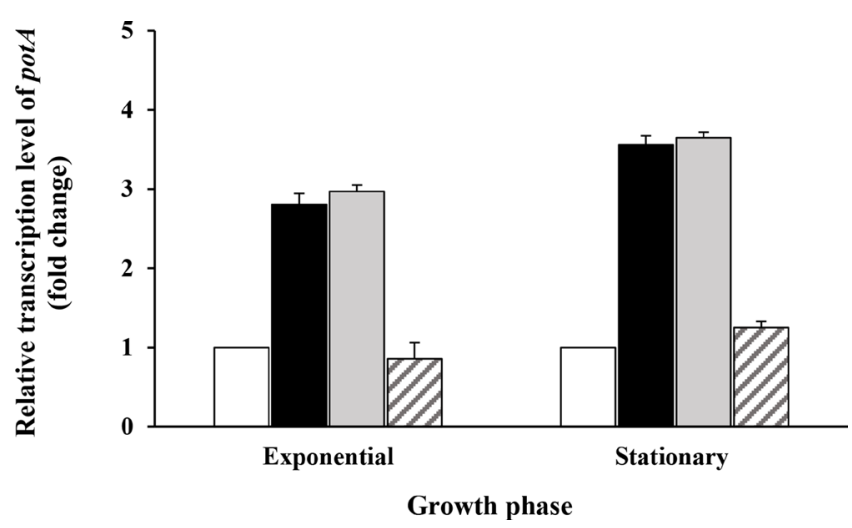

Fig. 5. Induction of pot $A B C D$ by polyamines at pH 7.4. qRT-PCR of potA transcripts was performed on RNA extracts of S. agalactiae A909 grown to an $\mathrm{OD}_{600 \mathrm{~nm}}$ of 0.6 (exponential phase) or of 1.2 (stationary phase) at $37^{\circ} \mathrm{C}$ in a chemically defined medium buffered with $100 \mathrm{mM}$ HEPES at $\mathrm{pH} 7.4$, in the absence of polyamines (white bars) or in the presence of $1 \mathrm{mM}$ spermidine (black bars), $1 \mathrm{mM}$ spermine (grey bars) or $1 \mathrm{mM}$ putrescine (striped bars). Transcript levels of potA were normalized against recA transcript levels. Gene expressions are presented as fold change with regard to the level of potA transcripts during growth of S. agalactiae in the absence of polyamines. Results are presented as means \pm SD of three independent experiments. spermidine, $1 \mathrm{mM}$ spermine or $1 \mathrm{mM}$ putrescine were also noted (Fig. S1c-e, respectively). Furthermore, TLC analyses indicate that both the wild-type strain and the $\triangle p o t A B C D$ mutant efficiently import spermidine and spermine and putrescine faintly (Fig. 3a, b, respectively). Therefore, the pot $A B C D$ transporter is not the main and only importer of polyamine in S. agalactiae.

In conclusion, $S$. agalactiae does not have an absolute need of exogenous polyamines in its environment, does not encode any specific enzymes involved in the synthesis of polyamines, has an undetectable content of intracellular polyamines when grown in the absence of polyamines, and does not need the Pot $A B C D$ transporter for efficient in vitro growth in physiological conditions at $\mathrm{pH}$ 7.4. Bacterial species thus have different comportments with respect to polyamine requirement because, for optimal growth, $S$. pneumoniae, in which the polyamine biosynthesis pathways were inhibited, or strains of S. suis devoid of the polyamine biosynthesis pathways IIp, Is and IIs, show delayed growth after the deletion of genes encoding the PotABCD transporter $[19,58]$. Supplementation of growth media with polyamines was also shown to enhance the growth of certain bacteria such as E. coli mutants, which cannot synthesize polyamines, or Legionella pneumophila, which does not possess the enzymes required for polyamine biosynthesis $[59,60]$.

Exogenous polyamine supplementation greater than $1 \mathrm{mM}$ inhibited S. agalactiae in a dose-dependent manner (Fig. 4 and data not shown). The bactericidal effect of certain concentrations of polyamines was reported for several bacterial species, and particularly in Staphylococcus aureus, which is hypersensitive to these compounds, even at a physiological concentration $[19,61]$. The reason for this inhibitory effect is not completely understood. Several reports have described a relationship between the toxicity of polyamines towards Staphylococcus aureus and an increase of $\mathrm{pH}$ of the medium. It was suggested that polyamine toxicity is inversely proportional to the net cationic charge of polyamines since they become sequentially deprotonated at elevated $\mathrm{pH}[61,62]$. It was also found that Staphylococcus aureus polyamine sensitivity is mediated by menaquinone but is independent of respiration [61]. In E. coli, to avoid spermidine toxicity, high concentration of spermidine inhibit the polyamine $\mathrm{ABC}$ transporter, through the interaction of spermidine with PotA [28]. In addition, PotD is a retroactive regulator of the transcription of pot $A B C D$ [63]. It is not known if these mechanisms exist and are efficient in S. agalactiae.

\section{Spermine and spermidine induce the transcription of potABCD}

We tried to correlate the transport of polyamines with the level of transcription of the pot $A B C D$ operon. To that end, we quantified pot $A$ mRNA by qRT-PCR during growth of the bacteria in a chemically defined medium containing or lacking $1 \mathrm{mM}$ spermine, spermidine or putrescine. As shown in Fig. 5, spermidine and spermine induce the 
(a)

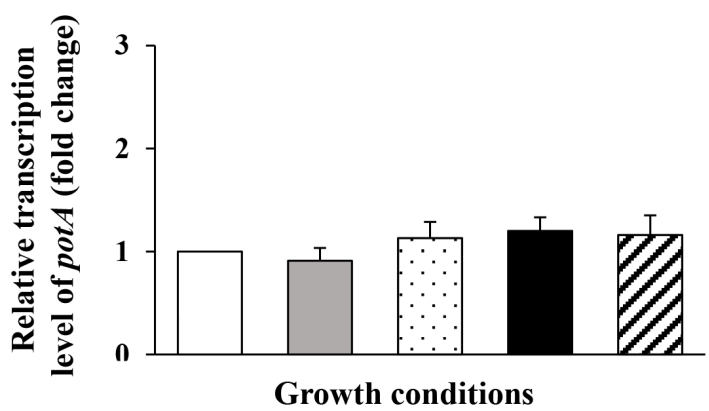

(c)

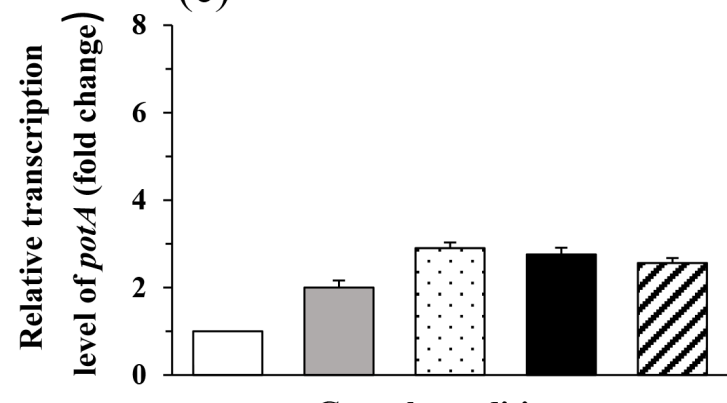

Growth conditions (b)

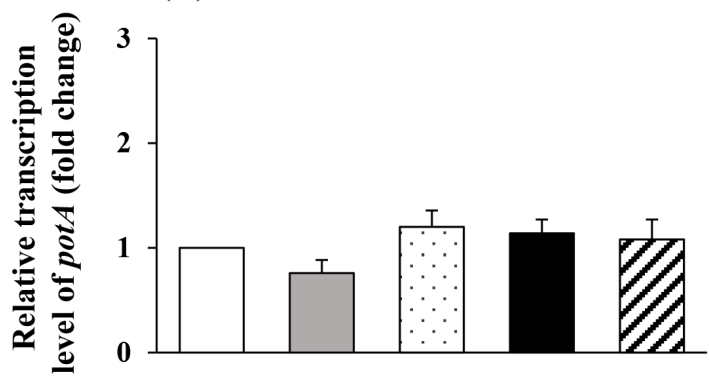

Growth conditions

(d)

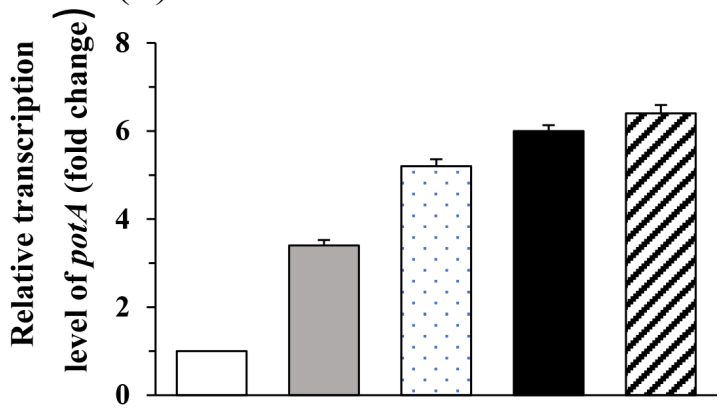

Growth conditions

Fig. 6. Expression of potABCD during acidic and peroxidase-induced oxidative stress in the presence or absence of polyamines. S. agalactiae $\mathrm{A} 909$ was grown at $37^{\circ} \mathrm{C}$ to an $\mathrm{OD}_{600 \mathrm{~nm}}$ of 0.6 (exponential phase) in $\mathrm{CDM}$ at pH 7.4. Bacterial cells were harvested (10 ml samples), and then either incubated for 30 min in CDM at pH 7.4 (a and b, white bars), in CDM buffered at pH 5.5 (a; grey, black, spotted and striped bars) and in CDM buffered at pH 4.0 (b; grey, black, spotted and striped bars), or incubated for 20 min (c) or 60 min (d) in $\mathrm{CDM}$ at pH 7.4 in the absence of $\mathrm{H}_{2} \mathrm{O}_{2}$ (white bars), or in the presence of $5 \mathrm{mM} \mathrm{H}_{2} \mathrm{O}_{2}$ (c and d, grey, black, spotted and striped bars). The CDM used for the incubation of the bacteria contained no polyamine (white and grey bars), or contained 1 mM spermidine (dotted bars), $1 \mathrm{mM}$ spermine (black bars) or $1 \mathrm{mM}$ putrescine (striped bars). After incubation, RNAs were extracted and qRT-PCR of potA and recA transcripts were performed. Transcript levels of each gene were normalized against recA transcript levels. Gene expressions are presented as fold change with regard to the level of potA transcripts during growth of S. agalactiae in normal conditions at pH $7.4 \mathrm{without}$ any addition. Results are presented as means \pm SD of three independent experiments.

expression of pot $A B C D$, during both the exponential (induction factor of 2.80 and 2.96, respectively) and the stationary phase (induction factor of 3.55 and 3.64, respectively) of growth. In contrast, putrescine does not have this effect. These data are in agreement with the intracellular polyamine content of cells grown in media with spermine, spermidine or putrescine (Fig. 3a).

Similarly, in S. suis, spermine and spermidine were found to induce the expression of the pot $A B C D$ operon, but related experiments in $S$. pneumoniae gave different results as the expression of potD was found to be down-regulated in the presence of spermidine but up-regulated in the presence of putrescine in a low choline medium $[4,19,41]$.

\section{Influence of polyamines and PotABCD on the resistance of $S$. agalactiae to acidic $\mathrm{pH}$}

The co-transcription of potABCD with $c l c$ and the role of polyamines as key mediators in the resistance to acidic stress of some bacteria could indicate a role of polyamines and of pot $A B C D$ in the acid resistance of $S$. agalactiae. We thus compared the growth of the wild- type strain $S$. agalactiae
A909 and the mutant A909 $\operatorname{pot} A B C D$ at the $\mathrm{pH}$ of two of its niches ( $\mathrm{pH} 5.5, \mathrm{pH}$ of the intestine; and $\mathrm{pH} 4.0, \mathrm{pH}$ of the vagina). To this end, these strains were grown in a chemically defined medium supplemented or not with $1 \mathrm{mM}$ spermidine, spermine or putrescine. As polyamines are very basic molecules, these media were buffered at pH 5.5 with $100 \mathrm{mM}$ MES or at $\mathrm{pH} 4.0$ with a $100 \mathrm{mM}$ mix of $\mathrm{Na}$ citrate and citric acid to avoid modifications of their $\mathrm{pH}$ after the addition of polyamines. Our results revealed no significant difference between the wild-type cells and the mutant at all the tested conditions at pH 5.5 (Fig. S2). As no growth of S. agalactiae strains could be obtained at $\mathrm{pH} 4.0$, either in the absence or in the presence of polyamines (results not shown), we compared the ability of the two strains to survive at $\mathrm{pH} 4.0$. To this end, strains A909 and $A 909 \triangle$ pot $A B C D$ were incubated in the above cited media and the proportion of surviving bacteria was monitored over time. No significant difference in the survival capacity of the mutant A909 $\triangle$ potABCD in comparison to the wild-type strain was visible, either in the absence or in the presence of polyamines (Fig. S3). 
We then compared the expression of the pot $A B C D$ operon at $\mathrm{pH} 7.4,5.5$ and 4.0 by qRT-PCR. Our results show that acidic stress at $\mathrm{pH} 5.5$ or at $\mathrm{pH} 4.0$ have no effect on the expression of potA, either in the absence or in the presence of polyamines (Fig. 6a, b). These expression data correlate with phenotypic observations, since deletion of the PotABCD transporter had no effect on the growth or the survival of $S$. agalactiae under acidic conditions (Figs S2 and S3). However, TLC analyses indicate that both the wild-type strain and the $\triangle$ pot $A B C D$ mutant import spermidine and spermine efficiently and putrescine very faintly at $\mathrm{pH} 5.5$ (Fig. S4). Hence, the PotABCD transporter is not involved in the resistance of strain A909 of S. agalactiae to acidic stress. However, this property is probably strain-dependent as a microarray analysis of strain $2603 \mathrm{~V} / \mathrm{R}$ showed that transcription of the murB-pot $A B C D$ operon (but not of the clc gene) is increased at $\mathrm{pH} 5.5$ relative to that at $\mathrm{pH} 7.0$ [63]. This induction was found to be dependent of the CsrRS two-component system (CovRS system), which is the major acid response regulator in that organism $[64,65]$.

\section{Influence of polyamines and PotABCD on the resistance of $S$. agalactiae to peroxide-induced oxidative stress}

In several bacterial species, polyamines, by their function as radical scavengers, were implied in the protection from the toxic effects of reactive oxygen, so we tested if PotABCD has a role in this mechanism in S. agalactiae [2-4, 66, 67]. To this end, exponentially growing pot $A B C D$ deletion mutant and wild-type strains were exposed to different concentrations of exogenous $\mathrm{H}_{2} \mathrm{O}_{2}(1,5$ and $20 \mathrm{mM})$. The proportion of surviving bacteria was monitored over time, by plate counts. No significant differences in survival rate were obtained between strain A909 and A909 $\triangle$ potABCD (Fig. S5). We next tested if polyamines are involved in the survival of the same strains submitted to an oxidative stress of $5 \mathrm{mM} \mathrm{H}_{2} \mathrm{O}_{2}$. Again, the wild-type and the mutant strains died at the same rate, whether the growth medium was supplemented or not with spermidine, spermine or putrescine (Fig. S6). We then compared the expression of the pot $A B C D$ operon by qRT-PCR in the absence or in the presence of $\mathrm{H}_{2} \mathrm{O}_{2}$. Hydrogen peroxyde significantly induced the expression of the pot $A B C D$ operon by 2 -fold after $20 \mathrm{~min}$ of incubation and by 3.4 -fold after $60 \mathrm{~min}$ of incubation (Fig. 6c). The presence of polyamines in the medium during a peroxidase-induced oxidative stress of $60 \mathrm{~min}$ again enhanced the expression of this operon by 5.2-, 6.0- or 6.4-fold in the presence of spermidine, spermine or putrescine, respectively (Fig. 6d).

The above expression data suggest an involvement of PotABCD and polyamines in the resistance of $S$. agalactiae to peroxidase-induced oxidative stress. These data were confirmed by TLC analyses of the intracellular content of cells grown in the presence of polyamines during oxidative stress. In these conditions, the wild-type strain imports spermidine and spermine but also, now, a noticeable amount of putrescine (Fig. 3c). By contrast, only a small quantity of spermine and spermidine are transported by the $\triangle$ pot $A B C D$ mutant (Fig. $3 \mathrm{~d}$, white arrows). The absence of visible phenotypic effects after deletion of the pot $A B C D$ operon should be explained by this slight transport of polyamines by as yet unidentified polyamine transporter(s). In S. pneumoniae, it was also shown that the pot $A B C D$ operon is induced during a peroxidase-induced oxidative stress. The $S$. pneumoniae pot $A B C D$ deletion mutant had nevertheless a comparable survival rate to the wild-type strain under exposure to the oxidizing stress-inducing agent paraquat $[4,54]$. However, different situations exist in the bacterial world as polyamine-deficient mutants of $E$. coli are killed in the presence of concentrations of oxygen that are non-toxic to wild-type cells [3].

\section{Conclusion}

In several bacterial species, PotABCD is able to transport different types of polyamines with different affinities. In a pioneering work on E. coli, Kashiwagi concluded that the order of preference of PotABCD is first putrescine, then spermidine and finally spermine [68]. However, this order of preference seems to vary between species $[19,41,69]$. In $S$. agalactiae, depending on the environment of the bacteria, the expression of pot $A B C D$ is induced by different types of polyamines. The import of each of these polyamines thus appears to depend on their affinity towards PotABCD but also on the availability of this transporter, both being governed by the living environment of the bacteria. The suspected redundancy of some polyamine transporters of Streptococcus species was suggested to mask some of their phenotypic traits $[4,54]$. A similar situation exists also in S. agalactiae, making the analysis of these important transporters yet more complex.

Funding information

S.K. was supported by PhD fellowships of the Lebanese University and AZM and SAADÉ and of the Lebanese Association for Scientific Research (LASeR), and by funding from the Human Resources Department (International Mobility Service) of INRAE and from the University Foundation Rabelais (University of Tours).

Conflicts of interest

The authors declare that there are no conflicts of interest.

\section{References}

1. Miyamoto S, Kashiwagi K, Ito K, Watanabe S, Igarashi K. Estimation of polyamine distribution and polyamine stimulation of protein synthesis in Escherichia coli. Arch Biochem Biophys 1993;300:63-68.

2. Shah $P$, Swiatlo E. A multifaceted role for polyamines in bacterial pathogens. Mol Microbiol 2008;68:4-16.

3. Chattopadhyay MK, Tabor CW, Tabor H. Polyamines protect Escherichia coli cells from the toxic effect of oxygen. Proc Natl Acad Sci USA 2003;100:2261-2265.

4. Shah P, Romero DG, Swiatlo E. Role of polyamine transport in Streptococcus pneumoniae response to physiological stress and murine septicemia. Microb Pathog 2008:45:167-172.

5. Lee YH, Kim BH, Kim JH, Yoon WS, Bang SH, et al. CadC has a global translational effect during acid adaptation in Salmonella enterica serovar Typhimurium. J Bacteriol 2007;189:2417-2425. 
6. Moreau PL. The lysine decarboxylase CadA protects Escherichia coli starved of phosphate against fermentation acids. J Bacteriol 2007;189:2249-2261.

7. Tabor CW, Tabor H. Polyamines in microorganisms. Microbiol Rev 1985:49:81-99.

8. Igarashi K, Kashiwagi K. Polyamine transport in bacteria and yeast. Biochem J 1999;344 Pt 3:633-642.

9. Nakada $Y$, Itoh Y. Identification of the putrescine biosynthetic genes in Pseudomonas aeruginosa and characterization of agmatine deiminase and $\mathrm{N}$-carbamoylputrescine amidohydrolase of the arginine decarboxylase pathway. Microbiology (Reading) 2003;149:707-714.

10. Hanfrey CC, Pearson BM, Hazeldine S, Lee J, Gaskin DJ, et al. Alternative spermidine biosynthetic route is critical for growth of Campylobacter jejuni and is the dominant polyamine pathway in human gut microbiota. J Biol Chem 2011;286:43301-43312.

11. Potter AJ, Paton JC. Spermidine biosynthesis and transport modulate pneumococcal autolysis. J Bacteriol 2014;196:3556-3561.

12. Applebaum DM, Dunlap JC, Morris DR. Comparison of the biosynthetic and biodegradative ornithine decarboxylases of Escherichia coli. Biochemistry 1977;16:1580-1584.

13. Kallio A, McCann PP. Difluoromethylornithine irreversibly inactivates ornithine decarboxylase of Pseudomonas aeruginosa, but does not inhibit the enzymes of Escherichia coli. Biochem $J$ 1981;200:69-75

14. Ohnuma M, Terui $Y$, Tamakoshi M, Mitome $H$, Niitsu $M$, et al. N1-aminopropylagmatine, a new polyamine produced as a key intermediate in polyamine biosynthesis of an extreme thermophile, Thermus thermophilus. J Biol Chem 2005;280:30073-30082.

15. Morimoto N, Fukuda W, Nakajima N, Masuda T, Terui Y, et al. Dual biosynthesis pathway for longer-chain polyamines in the hyperthermophilic archaeon Thermococcus kodakarensis. J Bacteriol 2010;192:4991-5001.

16. Lee J, Sperandio V, Frantz DE, Longgood J, Camilli A, et al. An alternative polyamine biosynthetic pathway is widespread in bacteria and essential for biofilm formation in Vibrio cholerae. J Biol Chem 2009:284:9899-9907.

17. Hamasaki-Katagiri N, Katagiri Y, Tabor CW, Tabor H. Spermine is not essential for growth of Saccharomyces cerevisiae: identification of the SPE4 gene (spermine synthase) and characterization of a spe4 deletion mutant. Gene 1998;210:195-201.

18. Michael AJ. Polyamines in eukaryotes, bacteria, and archaea. J Biol Chem 2016;291:14896-14903.

19. Liu W, Tan M, Zhang C, Xu Z, Li L, et al. Functional characterization of murB-potABCD operon for polyamine uptake and peptidoglycan synthesis in Streptococcus suis. Microbiol Res 2018;207:177-187

20. Lombardo MJ, Miller CG, Rudd KE. Physical mapping of the Escherichia coli pepT and potABCD genes. J Bacteriol 1993:175:7745-7746.

21. Kashiwagi K, Pistocchi R, Shibuya S, Sugiyama S, Morikawa K, et al. Spermidine-preferential uptake system in Escherichia coli. Identification of amino acids involved in polyamine binding in PotD protein. J Biol Chem 1996;271:12205-12208.

22. Kashiwagi K, Hosokawa N, Furuchi T, Kobayashi H, Sasakawa C, et al. Isolation of polyamine transport-deficient mutants of Escherichia coli and cloning of the genes for polyamine transport proteins. J Biol Chem 1990;265:20893-20897.

23. Pistocchi R, Kashiwagi K, Miyamoto S, Nukui E, Sadakata Y, et al. Characteristics of the operon for a putrescine transport system that maps at 19 minutes on the Escherichia coli chromosome. J Biol Chem 1993;268:146-152.

24. Tettelin H, Nelson KE, Paulsen IT, Eisen JA, Read TD, et al. Complete genome sequence of a virulent isolate of Streptococcus pneumoniae. Science 2001;293:498-506.

25. Baba T, Takeuchi F, Kuroda M, Yuzawa H, Aoki K, et al. Genome and virulence determinants of high virulence community-acquired MRSA. Lancet 2002;359:1819-1827.
26. Read TD, Peterson SN, Tourasse N, Baillie LW, Paulsen IT, et al. The genome sequence of Bacillus anthracis Ames and comparison to closely related bacteria. Nature 2003:423:81-86.

27. Fléchard M, Gilot $P$, Héry-Arnaud G, Mereghetti L, Rosenau A Analysis and identification of IS1548 insertion targets in Streptococcus agalactiae. FEMS Microbiol Lett 2013;340:65-72.

28. Kashiwagi K, Innami A, Zenda R, Tomitori $H$, Igarashi K. The ATPase activity and the functional domain of PotA, a component of the sermidine-preferential uptake system in Escherichia coli. J Biol Chem 2002;277:24212-24219.

29. Lancefield RC. A serological differentiation of human and other groups of hemolytic streptococci. J Exp Med 1933;57:571-595.

30. Schuchat A. Epidemiology of group B streptococcal disease in the United States: shifting paradigms. Clin Microbiol Rev 1998:11:497-513.

31. Stoll BJ, Hansen NI, Sánchez PJ, Faix RG, Poindexter BB, et al. Early onset neonatal sepsis: the burden of group B Streptococcal and E. coli disease continues. Pediatrics 2011;127:817-826.

32. Phares CR, Lynfield R, Farley MM, Mohle-Boetani J, Harrison LH, et al. Active bacterial core surveillance/emerging infections program network. Epidemiology of invasive group B streptococcal disease in the United States, 1999-2005. JAMA 2008;299:2056-2065.

33. Verani JR, McGee L, Schrag SJ, Division of Bacterial Diseases, National Center for Immunization and Respiratory Diseases, Centers for Disease Control and Prevention (CDC). Prevention of perinatal group B streptococcal disease--revised guidelines from CDC, 2010. MMWR Recomm Rep 2010;59:1-36.

34. Evans JJ, Bohnsack JF, Klesius PH, Whiting AA, Garcia JC, et al. Phylogenetic relationships among Streptococcus agalactiae isolated from piscine, dolphin, bovine and human sources: a dolphin and piscine lineage associated with a fish epidemic in Kuwait is also associated with human neonatal infections in Japan. J Med Microbiol 2008;57:1369-1376.

35. Sitkiewicz I, Green NM, Guo N, Bongiovanni AM, Witkin SS, et al. Transcriptome adaptation of group B Streptococcus to growth in human amniotic fluid. PLoS One 2009:4:e6114.

36. Gao X-Y, Zhi X-Y, Li H-W, Klenk H-P, Li W-J. Comparative genomics of the bacterial genus Streptococcus illuminates evolutionary implications of species groups. PLoS One 2014;9:e101229.

37. Batista RP, Ferreira CR. Streptococcus agalactiae septicemia in a patient with diabetes and hepatic cirrhosis. Autops Case Rep 2015;5:35-43.

38. van der Mee-Marquet $N$, Domelier A-S, Salloum $M$, Violette J, Arnault L, et al. Molecular characterization of temporally and geographically matched Streptococcus agalactiae strains isolated from food products and bloodstream infections. Foodborne Pathog Dis 2009;6:1177-1183.

39. Dulaney EL, Marx LM. A folig acid linked system in bacterial cell wall synthesis? J Antibiot 1971;24:713-714.

40. Khazaal S, Al Safadi R, Osman D, Hiron A, Gilot P. Dual and divergent transcriptional impact of IS1548 insertion upstream of the peptidoglycan biosynthesis gene murB of Streptococcus agalactiae. Gene 2019;720

41. Ware D, Watt J, Swiatlo E. Utilization of putrescine by Streptococcus pneumoniae during growth in choline-limited medium. J Microbiol 2005:43:398-405

42. Kamio Y, Nakamura K. Putrescine and cadaverine are constituents of peptidoglycan in Veillonella alcalescens and Veillonella parvula. $J$ Bacteriol 1987;169:2881-2884.

43. Hirao T, Sato M, Shirahata A, Kamio Y. Covalent linkage of polyamines to peptidoglycan in Anaerovibrio lipolytica. J Bacteriol 2000;182:1154-1157.

44. Abeyrathne PD, Chami M, Stahlberg H. Biochemical and biophysical approaches to study the structure and function of the chloride channel (CIC) family of proteins. Biochimie 2016;128-129:154-162. 
45. Sambrook J, Russell DW. Molecular Cloning: A Laboratory Manual. CSHL Press, 2001.

46. Dower WJ, Miller JF, Ragsdale CW. High efficiency transformation of $E$. coli by high voltage electroporation. Nucleic Acids Res 1988;16:6127-6145.

47. Ricci ML, Manganelli R, Berneri C, Orefici G, Pozzi G. Electrotransformation of Streptococcus agalactiae with plasmid DNA. FEMS Microbiol Lett 1994;119:47-52.

48. Biswas I, Gruss A, Ehrlich SD, Maguin E. High-efficiency gene inactivation and replacement system for gram-positive bacteria. J Bacteriol 1993;175:3628-3635.

49. Pedrol N, Tiburcio FA. Polyamines determination by TLC and HPLC. Handbook of Plant Ecophysiology Techniques 2001;chapter 21:335-363

50. Sekowska A, Coppée JY, Le Caer JP, Martin-Verstraete I, Danchin A. S-adenosylmethionine decarboxylase of Bacillus subtilis is closely related to archaebacterial counterparts. Mol Microbiol 2000;36:1135-1147

51. Swinscow TDV. Statistics at Square One. 4th edn. London: BMA; 1978.

52. Braibant $M$, Gilot $P$, Content J. The ATP binding cassette (ABC) transport systems of Mycobacterium tuberculosis. FEMS Microbiol Rev 2000;24:449-467.

53. Shah P, Marquart M, Quin LR, Swiatlo E. Cellular location of polyamine transport protein PotD in Streptococcus pneumoniae. FEMS Microbiol Lett 2006;261:235-237.

54. Shah P, Nanduri B, Swiatlo E, Ma Y, Pendarvis K. Polyamine biosynthesis and transport mechanisms are crucial for fitness and pathogenesis of Streptococcus pneumoniae. Microbiology (Reading) 2011;157:504-515.

55. Vassylyev DG, Tomitori H, Kashiwagi K, Morikawa K, Igarashi K. Crystal structure and mutational analysis of the Escherichia coli putrescine receptor. J Biol Chem 1998;273:17604-17609.

56. Naville M, Gautheret D. Transcription attenuation in bacteria: theme and variations. Brief Funct Genomics 2010;9:178-189.

57. Rosinski-Chupin I, Sauvage E, Sismeiro O, Villain A, Da Cunha V, et al. Single nucleotide resolution RNA-seq uncovers new regulatory mechanisms in the opportunistic pathogen Streptococcus agalactiae. BMC Genomics 2015;16:419

58. Ware D, Jiang Y, Lin W, Swiatlo E. Involvement of PotD in Streptococcus pneumoniae polyamine transport and pathogenesis. Infect Immun 2006;74:352-361.
59. Nasrallah GK, Riveroll AL, Chong A, Murray LE, Lewis PJ, et al. Legionella pneumophila requires polyamines for optimal intracellular growth. J Bacteriol 2011:193:4346-4360.

60. Yoshida T, Sakamoto A, Terui Y, Takao K, Sugita Y, et al. Effect of spermidine analogues on cell growth of Escherichia coli polyamine requiring mutant MA261. PLOS ONE 2016;11:e0159494.

61. Joshi GS, Spontak JS, Klapper DG, Richardson AR. Arginine catabolic mobile element encoded speG abrogates the unique hypersensitivity of Staphylococcus aureus to exogenous polyamines. Mol Microbiol 2011;82:9-20

62. Rozansky R, Bachrach U, Grossowicz N. Studies on the antibacterial action of spermine. J Gen Microbiol 1954;10:11-16.

63. AntognoniF, DelDucaS, Kuraishi A, Kawabe E, Fukuchi-ShimogoriT, et al. Transcriptional inhibition of the operon for the spermidine uptake system by the substrate-binding protein PotD. J Biol Chem 1999;274:1942-1948.

64. Santi I, Grifantini R, Jiang S-M, Brettoni C, Grandi G, et al. CsrRS regulates group B Streptococcus virulence gene expression in response to environmental $\mathrm{pH}$ : a new perspective on vaccine development. J Bacteriol 2009;191:5387-5397.

65. Lamy M-C, Zouine M, Fert J, Vergassola M, Couve E, et al. CovS/CovR of group B streptococcus: a two-component global regulatory system involved in virulence. Mol Microbiol 2004;54:1250-1268.

66. Khan AU, Di Mascio P, Medeiros MH, Wilson T. Spermine and spermidine protection of plasmid DNA against single-strand breaks induced by singlet oxygen. Proc Natl Acad Sci USA 1992;89:11428-11430.

67. Ha HC, Sirisoma NS, Kuppusamy P, Zweier JL, Woster PM, et al. The natural polyamine spermine functions directly as a free radical scavenger. Proc Natl Acad Sci USA 1998;95:11140-11145.

68. Kashiwagi K, Kobayashi H, Igarashi K. Apparently unidirectional polyamine transport by proton motive force in polyamine-deficient Escherichia coli. J Bacteriol 1986;165:972-977.

69. Yao X, Lu C-D. Functional characterization of the potRABCD operon for spermine and spermidine uptake and regulation in Staphylococcus aureus. Curr Microbiol 2014;69:75-81.

Edited by: I. Martin-Verstraete and F. M. Commichau

\section{Five reasons to publish your next article with a Microbiology Society journal}

1. The Microbiology Society is a not-for-profit organization.

2. We offer fast and rigorous peer review - average time to first decision is 4-6 weeks.

3. Our journals have a global readership with subscriptions held in research institutions around the world.

4. $80 \%$ of our authors rate our submission process as 'excellent' or 'very good'.

5. Your article will be published on an interactive journal platform with advanced metrics.

Find out more and submit your article at microbiologyresearch.org. 